\title{
Synapse Formation and Preferential Distribution in the Granule Cell Layer by Regenerating Retinal Ganglion Cell Axons Guided to the Cerebellum of Adult Hamsters
}

\author{
T. J. Zwimpfer, A. J. Aguayo, and G. M. Bray \\ Centre for Research in Neuroscience, The Montreal General Hospital Research Institute and McGill University, Montreal, \\ Quebec, Canada H3G 1 A4
}

To investigate constraints and preferences for synaptogenesis in the injured mammalian CNS, regenerating retinal ganglion cell (RGC) axons of adult hamsters were guided through a peripheral nerve (PN) graft to a target they do not usually innervate: the cerebellum $(\mathbf{C b})$. When identified by the presence of HRP anterogradely transported from the retina 2-9 months later, such RGC axons were found to have extended into the cerebellar cortex for up to $650 \mu \mathrm{m}$. Most of this growth was in the granule cell layer (GCL) and only a few axons entered the molecular layer. The preference for the GCL could not be explained by the position of the PN graft in the $\mathbf{C b}$, a selective denervation of the $\mathrm{GCL}$, local damage to other neurons, or the distribution of reactive gliosis in the vicinity of the graft. Furthermore, by EM, more than $95 \%$ of the labeled retinocerebellar terminals and synapses were in the GCL. Retinocerebellar terminals were larger and contained more synapses than the regenerated RGC terminals previously studied in the superior colliculus. These results indicate that regenerating axons of CNS neurons can form persistent synapses with novel targets. The preferential synaptogenesis in the GCL suggests that such unusual connections are not formed randomly in the CNS of these adult mammals.

After optic nerve (ON) transection in adult rats (Vidal-Sanz et al., 1987, 1991) or hamsters (Carter et al., 1989; Keirstead et al., 1989; Sauvé et al., 1991), retinal ganglion cell (RGC) axons regenerate through a peripheral nerve $(\mathrm{PN})$ graft that joins the eye and the superior colliculus (SC) and establish functional synapses that persist in the $\mathrm{SC}$, a normal target of retinofugal axons. A prominent feature of this regenerated retinocollicular (RGC-SC) projection is the selective reinnervation of the superficial, retinorecipient layers of the SC(Vidal-Sanz et al., 1987;

\footnotetext{
Received June 17, 1991; revised Oct. 22, 1991; accepted Oct. 25, 1991.

The technical assistance of M. David J. Laganiere, S. Shinn, J. Trecarten, and W. Wilcox is gratefully acknowledged. We thank S. Wang and Dr. M. Abrahamowicz for statistical assistance, and Drs. D. Lawrence, M. Rasminsky, and C. Sotelo for reviewing earlier versions of the manuscript. T.J.Z. was supported by a Medical Research Council fellowship. The Medical Research Council of Canada, the Spinal Cord Research Foundation, the Multiple Sclerosis Society of Canada, and the Daniel Heumann Fund for Spinal Cord Research provided financial support. The laboratory in which these studies were carried out is part of the Canadian Network for the Study of Neural Regeneration and Functional Recovery.

Correspondence should be addressed to Dr. A. J. Aguayo, Centre for Research in Neuroscience, Montreal General Hospital, 1650 Cedar Avenue, Montreal, Quebec, Canada, H3G 1 A4.

Copyright (c) 1992 Society for Neuroscience $0270-6474 / 92 / 121144-16 \$ 05.00 / 0$
}

Carter et al., 1989) rather than the deeper layers, which normally receive nonretinal inputs. While this distribution suggests that regenerating retinal axons are capable of recognizing certain normal targets in adult mammals, the selective denervation of the superficial layers of the SC, caused in these experiments by the transection of the $\mathrm{ON}$, could have determined the distribution of these regenerated connections. Indeed, denervation of CNS targets can induce adjacent uninjured neurons to sprout collaterals into deafferented regions (Raisman, 1969, 1985; Cotman et al., 1981; Chen and Hillman, 1982; Rossi et al., 1989) and may result in the expression of molecules that promote selective axonal ingrowth (Needels et al., 1986; Crutcher, 1987). Furthermore, in neonatal hamsters, developing retinal axons form anomalous connections in alternate nuclei that have lost their afferents (Kalil and Schneider, 1975; Frost, 1981; Sur et al., 1988).

The use of PN grafts to facilitate and guide the lengthy regrowth of interrupted CNS axons permits the investigation of the synaptic predilections of axons that regenerate into different regions of the CNS of adult mammals. In the present studies, the regenerating axons of hamster RGCs were guided from the eye to the cerebellum $(\mathrm{Cb})$, a structure that is not normally innervated by retinal neurons during development (Frost, 1984) or in the adult (see below). In addition, the effects of partial denervation of the $\mathrm{Cb}$ on the extension and terminal differentiation of the RGC axons were assessed by interrupting the cerebellar peduncles in one group of animals.

Short accounts of this work have been published previously (Zwimpfer et al., 1989, 1990; Aguayo et al., 1990).

\section{Materials and Methods}

Grafting procedures. Adult female Syrian hamsters (Mesocricetus auratus), 90-120 d old, were ancsthetized with intraperitoneal sodium pentobarbital $(35 \mathrm{mg} / \mathrm{kg})$. The left optic nerve was exposed intraorbitally and completely transected immediately behind the globe, avoiding damage to blood vessels that enter the eye. A segment of autologous peroneal nerve, $3.5 \mathrm{~cm}$ in length, was excised from the leg and sutured to the ocular stump of the transected ON (Vidal-Sanz et al., 1987; Carter et al., 1989) (Fig. 1, top). The rest of the PN graft was placed under the scalp with the free end buried within the posterior neck muscles.

Six to 8 weeks later, when RGC axons had grown along the graft (Vidal-Sanz et al., 1987; Carter et al., 1989), the free end of the graft was exposed, desheathed, and teased into smaller branches. Each branch was inserted 2-3 mm deep into one of the folia of lobules V, VI, or VII of the cerebellar vermis (Larsell, 1952), to the right of the midline (Fig. 1, bottom). To denervate the cerebellar cortex as extensively as possible, mossy fiber (MF) and climbing fiber afferents were interrupted by transecting the right inferior and middle cerebellar peduncles in one group 


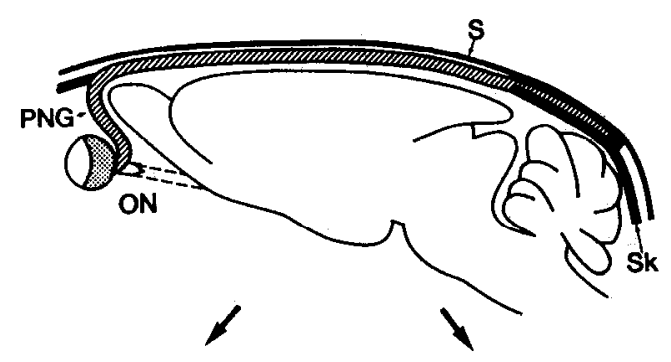

GROUP A
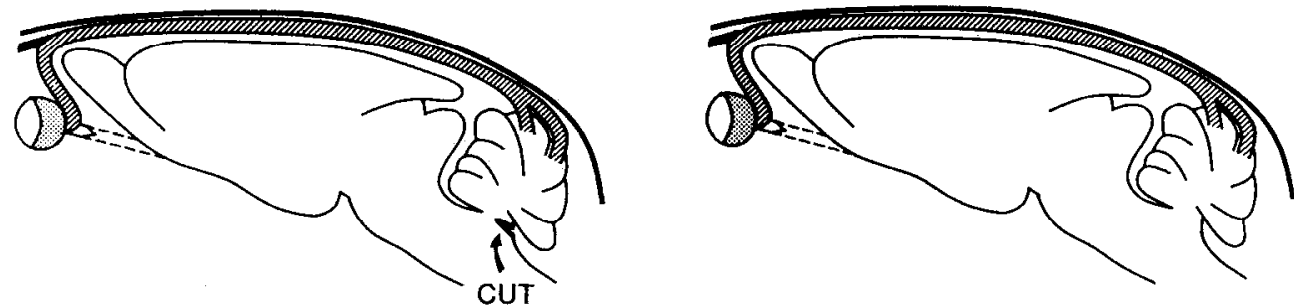

Figure 1. Grafting procedures. Top, An autologous peripheral nerve graft $(P N G)$ is sutured to the ON stump and placed under the scalp $(S)$. $S k$, skull. Bottom, Six weeks later, the distal end of the PNG is divided into branches and inserted into the right side of the cerebellar vermis. Group A, The right interior and middle cerebellar peduncles are transected (CUT). Group B, Cerebellar peduncles remain intact. of animals (group A). In other hamsters, the cerebellar peduncles were left intact (group B).

Labeling techniques. From 2 to 9 months after the graft was inserted into the $\mathrm{Cb}, 4 \mu \mathrm{l}$ of $30 \%$ HRP (Boehringer-Mannheim) were injected into the vitreous body of the left eye to label regenerating RGC axons and their terminals. Although there is no indication of a direct retinocerebellar connection in mammals, the possibility was nevertheless investigated in three intact adult hamsters by injecting HRP into one eye and examining the $\mathrm{Cb}$ for labeled axonal profiles.

To characterize normal mossy fiber (MF) terminals in the cerebellar vermis, HRP injections were performed in four control hamsters, matched for age with the experimental animals, to label terminals of cerebellar afferents by anterograde transport of the tracer. In three of these animals, five bilateral injections of $0.2 \mu \mathrm{l}$ of $30 \% \mathrm{HRP}$ were made into the lateral aspect of the cuneate tubercles (to label the external cuneate nucleus) and into the dorsal horns of the spinal cord from T12 to $\mathrm{L} 1$ (to label neurons in Clarke's column). Neurons in these nuclei project as mossy fibers to the $\mathrm{Cb}$ through the cuneocerebellar and dorsal spinocerebellar tracts, respectively. In one animal, injections were made bilaterally into the pons and rostral medulla, $1-2 \mathrm{~mm}$ deep to the floor of the fourth ventricle and extending from 1 to $5 \mathrm{~mm}$ rostral to the obex to label pontine and other brainstem nuclei that are sources of MF input to the $\mathrm{Cb}$; such injections are also likely to label neurons in the inferior olivary nucleus, the major source of climbing fiber afferents to the $\mathrm{Cb}$.

Anatomical analyses. Two days after injection of HRP, PN-grafted and normal animals were perfused with $0.9 \% \mathrm{NaCl}$ followed by a solution of $2.5 \%$ glutaraldehyde and $0.5 \%$ formaldehyde prepared from paraformaldehyde. The cerebellar vermis was removed together with the caudal end of the PN graft. Serial sagittal sections of the right cerebellar vermis, $50-70 \mu \mathrm{m}$ thick, were cut on a vibrating microtome and processed for HRP histochemistry. The sections were first incubated at pH 4.0 with tetramethylbenzidine (TMB); the reaction product was then stabilized with diaminobenzidine-cobalt (DAB-Co) at pH 7.4 (Lemann et al., 1985). Sections were stained with osmium tetroxide, flat embedded in epoxy resin, and examined by light microscopy. Camera lucida drawings of HRP-labeled axons within the $\mathrm{Cb}$ were prepared from serial sections. Due to the discontinuity of the HRP labeling obtained with these techniques, it was not possible to estimate accurately the number of axons that entered the $\mathrm{Cb}$ from the grafts or to trace the entire course of most arbors. Despite these limitations, the maximum distance that RGC axons extended into the $\mathrm{Cb}$ could be measured in each animal. By reviewing all the 50-70- $\mu \mathrm{m}$-thick sections in which RGC axons were seen to enter the $\mathrm{Cb}$, growth of labeled axons into the granular and/or molecular layers (ML) was estimated qualitatively for each PN graft according to the following scale: 0 , none; + , sparse; $2+$, moderate; $3+$, large; $4+$, very extensive (examples are illustrated in Figs. 2,3 ).

From the 17 experimental animals in which retinal axons grew into the $\mathrm{Cb}, 13$ animals were selected at random, and sections of their cer- ebellar vermis were processed for EM. Areas of the Cb showing HRPlabeled fibers were sectioned for EM in the four control animals. Of the 202 HRP-labeled retinocerebellar terminals and $516 \mathrm{MF}$ terminals, 97\% had maximum diameters of less than $8.6 \mu \mathrm{m}$ and $8.9 \mu \mathrm{m}$, respectively. Therefore, to minimize the chance of a repeated sampling of the same terminal, only terminals found in sections separated by at least $9 \mu \mathrm{m}$ were selected for morphometric and statistical analysis. The group of normal MF terminals comprised only labeled terminals in the granule cell layer (GCL) of lobules V, VI, and VII of the cerebellar vermis.

The perimeters of HRP-labeled terminals in electron micrographs printed at 35,000 $\times$ were outlined using an IBAS-I tablet digitizer, and terminal areas, perimeters, and maximum diameters were calculated. Portions of the parent axon that contained visible microtubules and neurofilaments were not included as part of the terminal. Synapses were identified by the presence of pre- and postsynaptic densities, vesicles adjacent to the presynaptic density, and a visible synaptic cleft. The number of synapses $/ 10 \mu \mathrm{m}$ of terminal perimeter was calculated for each individual terminal.

Statistical methods. Maximum growth of RGC axons into the $\mathrm{Cb}$ of each experimental animal was compared between $\mathrm{RGC}-\mathrm{Cb}$ animals in groups A and B by a two-tailed Student's $t$ test for independent samples. Correlation coefficients for maximum axonal ingrowth and survival time were calculated with the GBSTATL ${ }^{3}$ program. The proportions of terminals and synapses in the granule cell layer of the $\mathrm{Cb}$ were also compared between animals in groups $\mathrm{A}$ and $\mathrm{B}$ by a Mann-Whitney $U$ test.

The SAS procedure GLM (SAS Institute, Inc., Cary, NC) was used for statistical analysis of the retinocerebellar (RGC-Cb) terminals and for comparisons with the MF (mossy fiber) terminals. Areas, perimeters, and synapses $/ 10 \mu \mathrm{m}$ perimeter of RGC-Cb and MF terminals were compared by an analysis of variance (ANOVA) for unbalanced nested design with the animal as the nested random factor. In this method, degrees of freedom are based on numbers of animals rather than numbers of terminals or synapses, and the error variance is estimated by the pooled within-group between-animal variance. Using this approach, the following analyses were performed. (1) To assess the effect of denervation, groups A (ipsilateral middle and inferior cerebellar peduncles transected) and $B$ (peduncles intact) were compared at each of the three survival times $(2,4-5$, and $7-9$ months; Table 1$)$. Because data were only available for one group $A$ animal at 7-9 months (Table 1), the within-group variance of group B at 7-9 months was used to estimate the error variance for this analysis. (2) Groups A and B were also compared by pooling the data for the three survival times. (3) Age effects were tested by pooling the data from groups A and B. (4) We also carried out a two-way ANOVA with age and experimental condition (denervation by interrupting the cerebral peduncles) as crossed factors. In addition to adjusting the estimated effect of one factor for that of the other, this analysis also provided a test of the interaction between the 
Table 1. Growth of RGC axons from PN grafts connecting the eye and the $\mathrm{Cb}$

\begin{tabular}{|c|c|c|c|c|c|}
\hline Group A & & & Group B & & \\
\hline Animal & $\begin{array}{l}\text { Survival }^{a} \\
\text { (months) }\end{array}$ & $\begin{array}{l}\text { Ingrowth }{ }^{b} \\
(\mu \mathrm{m})\end{array}$ & Animal & $\begin{array}{l}\text { Survival }^{a} \\
\text { (months) }\end{array}$ & $\begin{array}{l}\text { Ingrowth }^{b} \\
(\mu \mathrm{m})\end{array}$ \\
\hline 41 & 2 & 350 & 38 & 2 & 400 \\
\hline 62 & 2 & 650 & 67 & 2 & 190 \\
\hline 75 & 2 & 500 & 54 & 3 & 280 \\
\hline 48 & 4 & 450 & 53 & 4 & 260 \\
\hline 50 & 5 & 300 & 77 & 4 & 200 \\
\hline 103 & 5 & 300 & - & - & - \\
\hline 82 & 6 & 650 & - & - & - \\
\hline 65 & 7 & 400 & 102 & 8 & 150 \\
\hline 106 & 7 & 250 & 64 & 9 & 140 \\
\hline- & - & - & 80 & 9 & 500 \\
\hline Mean \pm SEM & & $428 \pm 49$ & & & $265 \pm 44^{*}$ \\
\hline
\end{tabular}

Group A, ipsilateral middle and inferior cerebellar peduncles transected; group B, cerebellar peduncles intact.

a Time after insertion of the graft into the $\mathrm{Cb}$.

${ }^{b}$ Maximum axonal extension beyond the end of the graft into the $\mathrm{Cb}$.

* Significantly less than group A, $t$ test, $p<0.03$.

two factors. (5) The data for groups $\mathrm{A}$ and $\mathrm{B}$, pooled for survival time, were also used to compare $\mathrm{RGC}-\mathrm{Cb}$ and $\mathrm{MF}$ terminals.

The possibility that a loss of Purkinje cells (PCs) contributed to the growth of RGC axons into the cerebellar cortex was also investigated. To assess PC loss caused by the insertion of the PN graft into the $\mathrm{Cb}$, the number of PC somata in a given area of cerebellar cortex was determined in 16 of the $17 \mathrm{RGC}$-Cb animals in which RGC axons grew into the $\mathrm{Cb}$ and in four normal animals of similar age and sex. PCs were identified by (1) their location at the interface between the granule cell and molecular layers, (2) the presence of visible nuclei and nucleoli, and (3) the characteristic shape and large size of their cell bodies. Purkinje cell somata were counted under light microscopy (LM) in every third 3- $\mu$ m-thick section of the cerebellar cortex. In the $16 \mathrm{RGC}-\mathrm{Cb}$ animals, counts were made in the region of the cerebellar cortex into which HRP-labeled RGC axons had grown from 21 individual PN grafts. The number of $\mathrm{PC}$ somata/ $1000 \mu \mathrm{m}$ length of $\mathrm{PC}$ layer was calculated for each $3 \mu \mathrm{m}$ section with an average of 13 sections examined for each of the PN grafts. The mean number of PC somata $/ 1000 \mu \mathrm{m}$ was estimated for each of the 21 grafts. For normal animals, PC somata were counted in comparable regions of lobules V, VI, and VII of the vermis and the mean was determined from an average of 34 sections examined per animal.

Because the course of RGC axonal growth into the $\mathrm{Cb}$ may have been influcnced by the distribution of reactive gliosis induced by insertion of the graft into the $\mathrm{Cb}$, immunoreactivity to glial fibrillary acidic protein (GFAP), a marker of reactive astrocytes (Bignami and Dahl, 1976), was investigated in the cerebellar regions surrounding the graft tip in three hamsters. A peripheral nerve segment was inserted into the $\mathrm{Cb}$, and $2-$ 3 months later the animals were perfused with $4 \%$ paraformaldehyde. Sections $20 \mu \mathrm{m}$ thick were incubated overnight with a rabbit polyclonal anti-GFAP IgG (Sigma, St. Louis, MO) at a dilution of 1:200, followed by a fluorescein-labeled goat anti-rabbit IgG, diluted 1:50. Sections of the cerebellar vermis were examined with the fluorescence microscope.

Three intact hamsters received intravitreal injections of HRP. No direct retinal projection to the cerebellar vermis was found on LM examination. The superficial layers of the contralateral superior colliculus of these hamsters were extensively labeled; patchy labeling was also found in the ipsilateral SC (Carter et al., 1991b).

\section{Results}

In 25 hamsters with RGC-Cb grafts, 15 in group A (ipsilateral middle and inferior cerebellar peduncles transected) and 10 in group B (intact peduncles), HRP-labeled axons extended to the end of the PN graft inserted into the cerebellar vermis. Such regenerated RGC axons grew beyond the end of the graft and into the $\mathrm{Cb}$ in 17 of these animals, 9 in group $\mathrm{A}$ and 8 in group $B$ (Table 1). These labeled axons originated from a total of 22 different branches of the PN grafts, 11 in each of group A and B. The RGC axons grew from two branches in each of 5 animals and from single branches in the remaining 12 hamsters. No HRP-labeled cell bodies were seen in the $\mathrm{Cb}$ of any of the experimental animals studied.

In all 17 animals, labeled RGC axons grew more than 100 $\mu \mathrm{m}$ (range, $150-650 \mu \mathrm{m}$ ) into the gray matter of the cerebellar cortex (Table 1; Figs. 2, 3); growth into the white matter was observed in one animal but only for $50 \mu \mathrm{m}$ from the end of the graft. The longest distance covered by RGC axons within the $\mathrm{Cb}$ cortex of each animal was significantly greater (Student's $t$ test, $p<0.03)$ in animals of group A $(428 \pm 49 \mu \mathrm{m}$, mean \pm SEM) than group B $(265 \pm 44 \mu \mathrm{m})$ (Table 1). However, there was no significant correlation between the extent of axonal ingrowth and survival time after graft insertion into the $\mathrm{Cb}$ whether analyzed separately for group A (correlation coefficient, -0.55 ; $p=0.13$ ) and group B (correlation coefficient, $0.06 ; p=0.88$ ), or pooled for the two groups (correlation coefficient, $-0.29 ; p$ $=0.25$ ).

The RGC axons grew a maximum of $650 \mu \mathrm{m}$ into the GCL (Fig. $3 d$ ) but only up to $200 \mu \mathrm{m}$ in the ML (Fig. $3 h$ ). In four animals, the regenerating axons formed distinct, multibranched arbors (Figs. 2, 3b,d,e); such branching was only observed in the GCL. Detailed comparisons of the incidence and extent of retinal arborizations in the $\mathrm{Cb}$ and those obtained previously when RGCs regenerated into the SC (Carter et al., 1991a) were not possible because the tracing techniques used in the present experiments cannot define the entire course of retinal axons in either of these targets. Similarly, it has not been possible to determine unequivocally how many of the labeled profiles are branches of a single axon rather than separate individual axons.

\section{Distribution of $R G C$ axons and synapses in the cerebellar cortex}

In 14 of the 17 animals in which RGC axons entered the $\mathrm{Cb}$, axons grew either exclusively or predominantly into the GCL. Growth into the ML was always sparse (Figs. 2, 3), even in the 

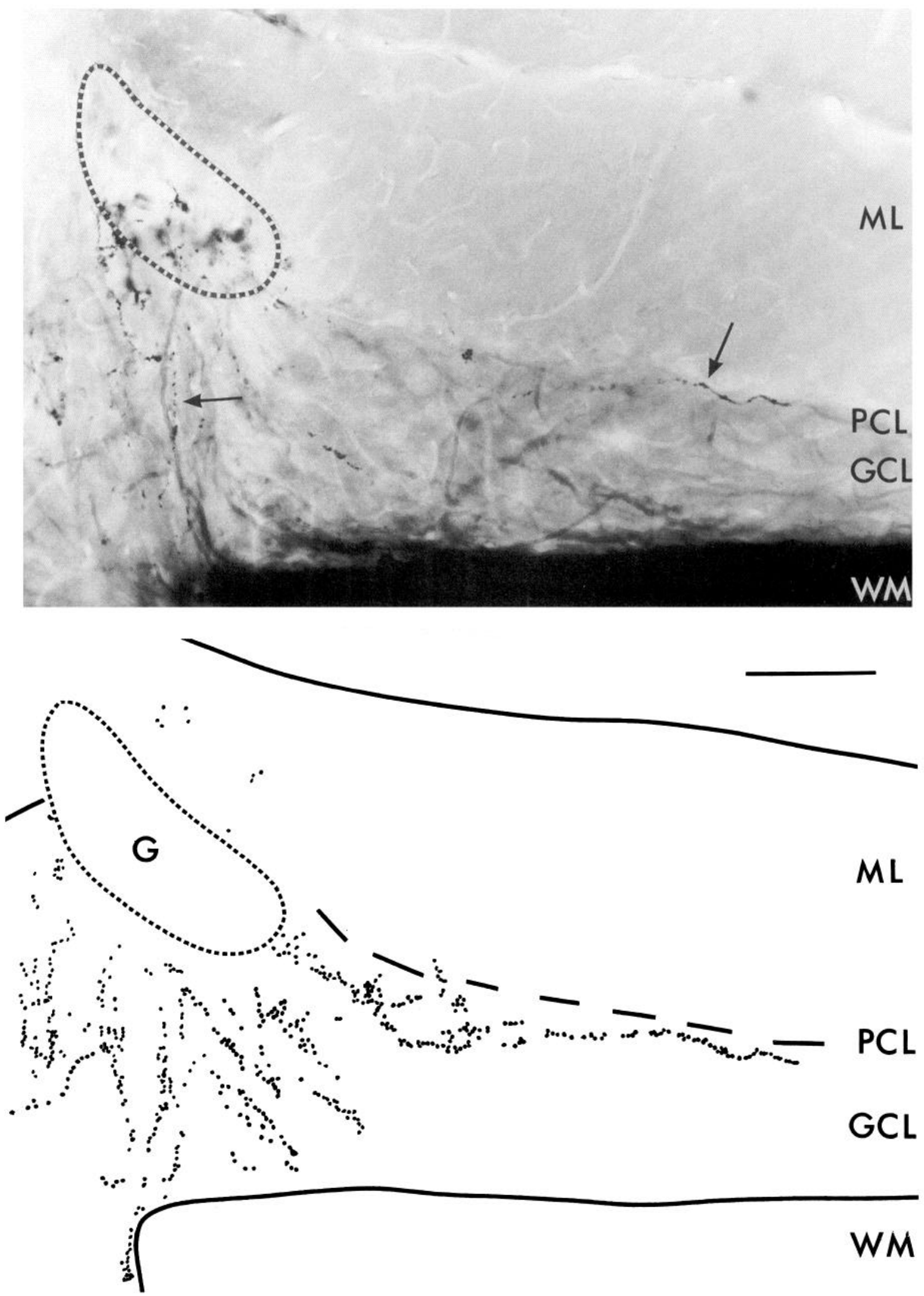

Figure 2. Extension of regenerated RGC axons into the $\mathrm{Cb}$. A, Light micrograph. Linearly arranged HRP reaction product (small black dots) indicates the RGC axons (arrows) that have grown from the end of a PN graft (outlined by the broken line) and into the Cb. At this plane of focus, the HRP-labeled axons were only observed in the GCL. PCL, PC layer; $W M$, white matter. $B$, A camera lucida drawing demonstrates the HRPlabeled RGC axons seen at multiple planes of focus through the 70- $\mu \mathrm{m}$-thick section illustrated in $A$. RGC axons penetrated the cerebellum for up to $400 \mu \mathrm{m}$ from the end of the PN graft $(G)$ and were distributed predominantly in the GCL, where they appeared to branch. Growth was graded as $4+$ in the GCL and + in the ML (see Table 2). Scale bar, $100 \mu \mathrm{m}$. 
a

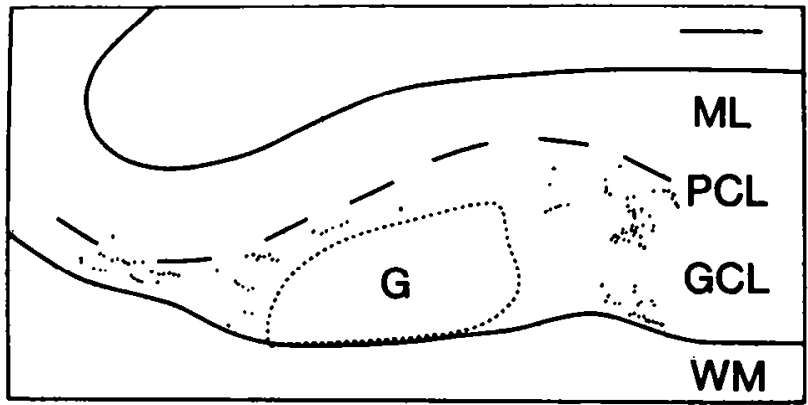

C

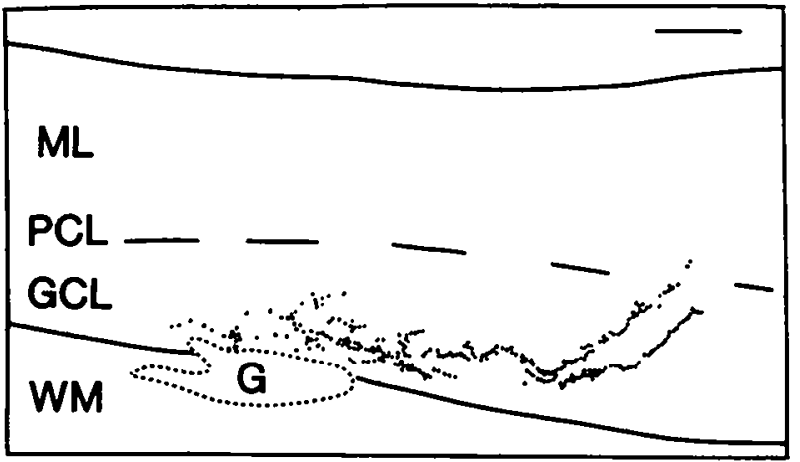

e

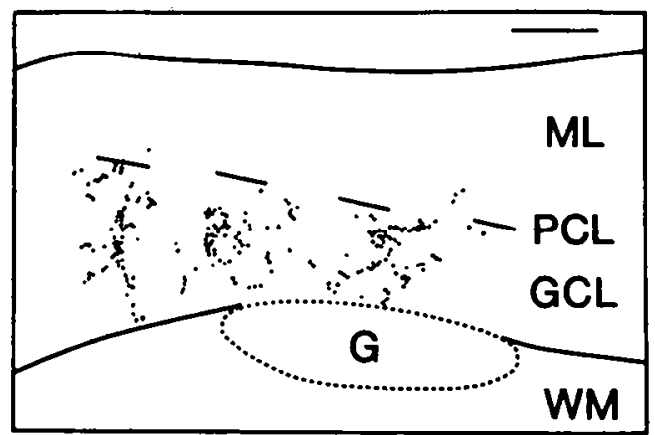

9

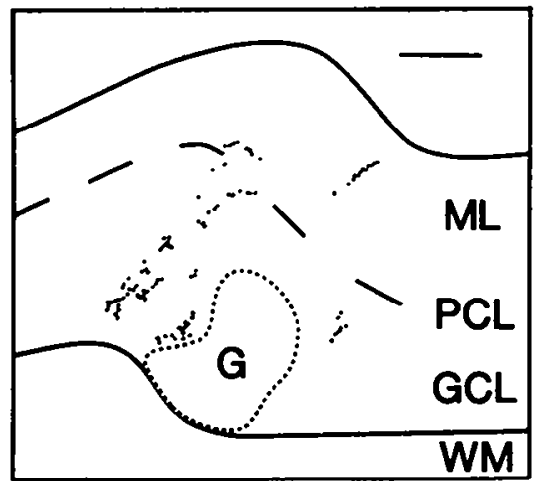

$\mathrm{h}$

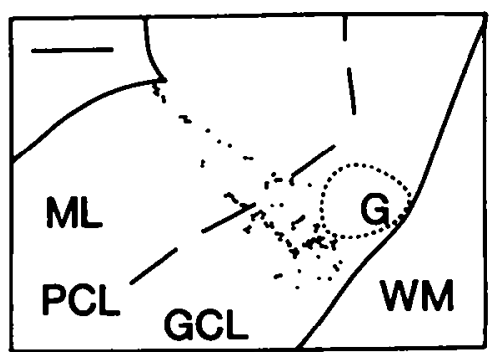

b
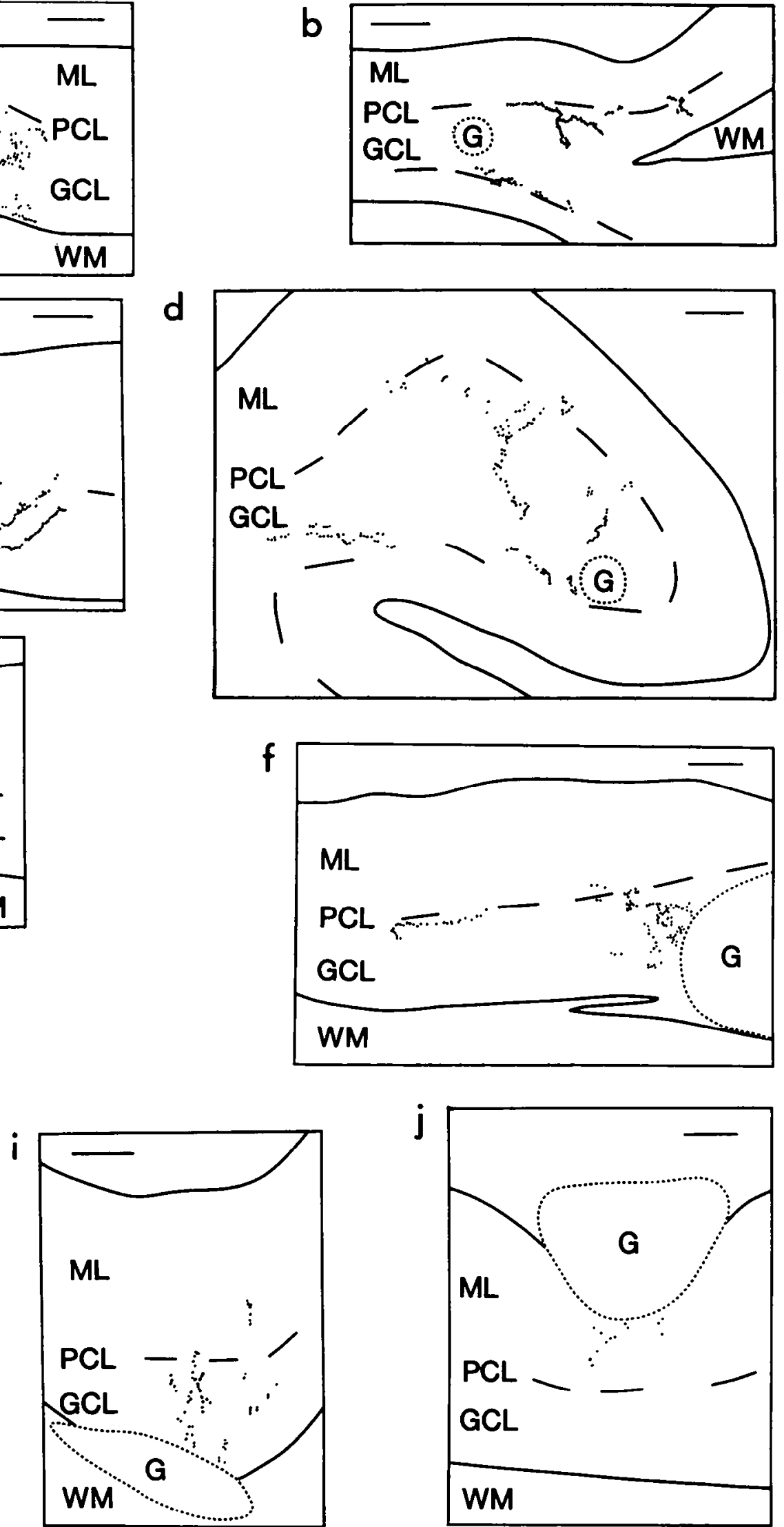

Figure 3. Distribution of RGC axon growth into the $\mathrm{Cb}$. These camera lucida drawings of individual 50-70- $\mu \mathrm{m}-\mathrm{thick}$ sections of the $\mathrm{Cb}$ demonstrate that HRP-labeled RGC axons (dots) penetrated the $\mathrm{Cb}$ for up to $650 \mu \mathrm{m}(d)$ from the end of the PN graft $(G)$ and, in all but one example $(j)$, were distributed predominantly within the GCL. Growth into the ML was sparse and only up to $200 \mu \mathrm{m}(h)$ even when the graft was in the ML $(j)$ or near the GCL-ML border $(a, b, d, f$, and $h)$. Retinal axons formed distinct arbors only in the GCL $(b, d$, and $e)$. Broken line, PC layer $(P C L)$; $W M$, white matter. Scale bars, $100 \mu \mathrm{m}$. 
Table 2. Growth of RGCs axons in the $\mathrm{Cb}$ in relation to the position of the PN graft and partial denervation

\begin{tabular}{|c|c|c|c|c|}
\hline \multirow{2}{*}{$\begin{array}{l}\text { Position of the } \\
\text { PN graft }\end{array}$} & \multirow{2}{*}{$\begin{array}{l}\text { Cere- } \\
\text { bellar } \\
\text { peduncles }\end{array}$} & \multicolumn{2}{|c|}{ RGC axon ingrowth* } & \multirow{2}{*}{$\begin{array}{l}\text { Illus- } \\
\text { trated } \\
\text { in } \\
\text { figure }\end{array}$} \\
\hline & & GCL & ML & \\
\hline \multirow[t]{2}{*}{ ML } & intact & 0 & + & \\
\hline & intact & 0 & + & $3 j$ \\
\hline \multirow[t]{5}{*}{ ML-GCL border } & cut & + & 0 & \\
\hline & cut & +++ & 0 & $3 d$ \\
\hline & cut & ++++ & + & 2 \\
\hline & intact & 0 & + & \\
\hline & intact & ++ & + & \\
\hline \multirow[t]{11}{*}{ GCL } & cut & ++ & 0 & \\
\hline & cut & +++ & 0 & $3 b$ \\
\hline & cut & +++ & 0 & \\
\hline & cut & ++++ & + & $3 a$ \\
\hline & cut & +++ & + & $3 e$ \\
\hline & intact & + & 0 & \\
\hline & intact & + & 0 & \\
\hline & intact & +++ & + & $3 g$ \\
\hline & intact & +++ & ++ & $3 h$ \\
\hline & intact & +++ & + & $3 f$ \\
\hline & intact & +++ & 0 & \\
\hline \multirow[t]{3}{*}{ GCL-WM border } & cut & ++ & + & \\
\hline & cut & ++++ & 0 & $3 c$ \\
\hline & cut & +++ & + & $3 i$ \\
\hline Unknown & intact & ++ & + & \\
\hline
\end{tabular}

* Qualitative assessment (see Materials and Methods for definitions) of the amount of axonal growth from 22 individual branches of PN grafts in the 17 experimental animals. WM, white matter.

three animals in which the RGC axons extended primarily into this layer (Table 2).

The HRP-labeled RGC terminals were found in each of the 13 animals examined by EM (Figs. 4, 5). A total of 202 labeled RGC-Cb terminals were identified in animals of groups $A$ and
B, of which $190(94 \%)$ were located in the GCL and 12 in the ML (Table 3). These 202 terminals formed 365 synapses, 353 $(97 \%)$ with neurons in the GCL and 12 in the ML (Table 3). The GCL was easily identified on EM by the characteristic ultrastructure of granule cell (GC) somata (Fig. 4, top): large nuclei, clumps of condensed nuclcar chromatin, and a thin rim of cytoplasm (Palay and Chan-Palay, 1974).

$P N$ graft location and the distribution of $R G C$ axons. To determine if the location of the PN graft in the $\mathrm{Cb}$ was responsible for the distribution of RGC axons and synapses in the cerebellar cortex, the position of the end of the graft was related to the location and extent of growth of the labeled axons. In all 11 animals with grafts that ended in the GCL ( 5 in group A and 6 in group B), and in 4 of the 5 animals (2 each in groups A and B) in which the graft was located at the ML-GCL border, RGC axons grew exclusively or predominantly within the GCL (Table 2). In only one of the five animals with grafts at the ML-GCL border, and in both animals in which the PN grafts ended in the ML, RGC axons grew into the ML, but in all instances, this growth was sparse (Table 2; Fig. 2, 3d,j). Thus, the preferential growth of regenerated RGC axons in the GCL did not correlate with the position of the PN graft.

Denervation and the distribution of $R G C$ axons, terminals, and synapses. RGC axons grew predominantly into the GCL from all $11 \mathrm{PN}$ grafts in group $\mathrm{A}$ animals (cerebellar peduncles cut) and from 8 of the 11 grafts in group B (peduncles intact) (Table 2). Of the $124 \mathrm{RGC}-\mathrm{Cb}$ terminals and 263 synapses identified in the group A animals, $123(99 \%)$ terminals and 261 (99\%) synapses were in the GCL. For the group B animals, 67 $(86 \%)$ of the $78 \mathrm{RGC}-\mathrm{Cb}$ terminals and $92(90 \%)$ of the 102 synapses were in the GCL. These proportions of terminals and synapses in the GCL of the group $A$ and $B$ animals were not significantly different (Mann-Whitney $U$ test, $p>0.1$ ). Although a preference of RGC axons for the GCL was observed in both groups, the extent of axonal growth in the GCL was greater in those with transected (group A) cerebellar peduncles. For 8 of the 11 group A grafts, the amount of axonal growth was graded as $3+$ or $4+$ while for 7 of the 11 group B grafts, this growth was graded as $0-2+$ (Table 2 ).

Table 3. Ultrastructural characteristics of axon terminals in the Cb

\begin{tabular}{|c|c|c|c|c|c|}
\hline & \multicolumn{4}{|c|}{ RGC-Cb ${ }^{a}$ (regenerated) } & \multirow[t]{3}{*}{ MF (normal) } \\
\hline & \multicolumn{3}{|c|}{ GCL } & \multirow{2}{*}{$\frac{\text { ML }}{\text { (Groups A + B) }}$} & \\
\hline & Group A & Group B & Groups A + B & & \\
\hline Animals $(n)$ & 6 & 6 & 12 & $3^{b}$ & 4 \\
\hline \multicolumn{6}{|l|}{ Terminals } \\
\hline Number & 123 & 67 & 190 & 12 & 516 \\
\hline Area $\left(\mu \mathrm{m}^{2}\right)^{c}$ & $5.8 \pm 0.9$ & $5.4 \pm 0.6$ & $5.6 \pm 0.5$ & $7.0 \pm 1.2$ & $7.4 \pm 0.4$ \\
\hline Perimeter $(\mu \mathrm{m})^{c}$ & $11.1 \pm 0.5$ & $11.0 \pm 1.1$ & $11.1 \pm 0.8$ & $10.5 \pm 1.5$ & $13.1 \pm 0.5$ \\
\hline Maximum diameter $(\mu \mathrm{m})^{r}$ & $4.1 \pm 0.2$ & $4.2 \pm 0.3$ & $4.1 \pm 0.2$ & $4.2 \pm 0.7$ & $4.3 \pm 0.1$ \\
\hline Pale mitochondria (\%) & 91 & 90 & 91 & 100 & 3 \\
\hline \multicolumn{6}{|l|}{ Synapses } \\
\hline Number & 261 & 92 & 353 & 12 & 849 \\
\hline Axodendritic (\%) & 99.7 & 100 & 99.7 & 100 & 100 \\
\hline Number/terminal ${ }^{d}$ & 2.5 & 1.5 & 2.0 & 1.3 & 1.6 \\
\hline Number $/ 10 \mu \mathrm{m}$ terminal perimeter & $2.0 \pm 0.3$ & $1.1 \pm 0.5$ & $1.5 \pm 0.2$ & $1.0 \pm 0.4$ & $1.2 \pm 0.1$ \\
\hline
\end{tabular}

\footnotetext{
${ }^{a}$ Values for individual animals are listed in Table 5.
}

${ }^{b}$ Two of the three animals with RGC terminals in the ML also had terminals within the GCL.

' Mean \pm SEM; nu statistically significant differences (ANOVA; see Results) among the groups.

${ }^{d}$ Mean. 

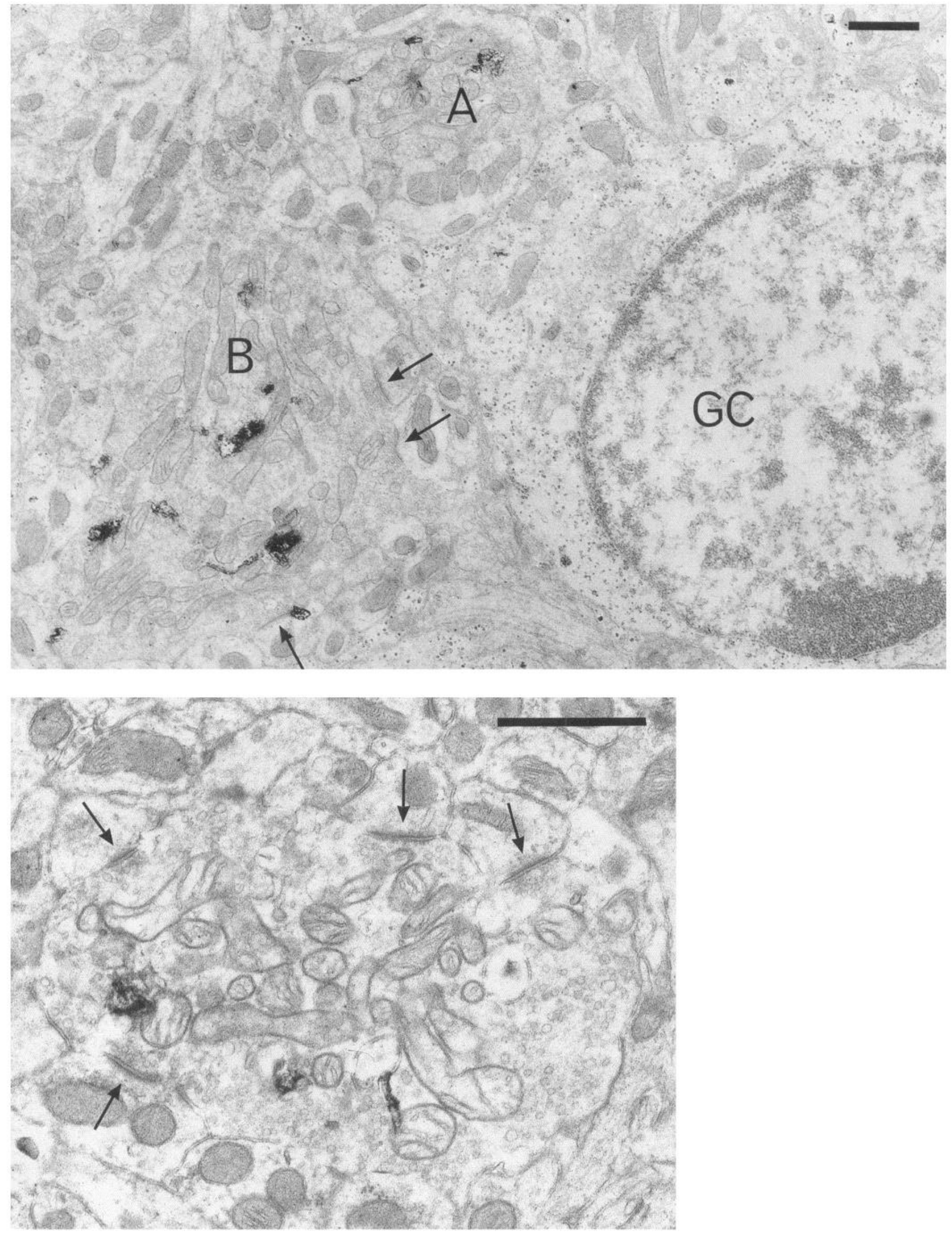

Figure 4. Terminals of RGC axons in the GCL of the Cb. Top. Two RGC axon terminals $(A, B)$ near a GC soma $(G C)$ are labeled with HRP reaction product (black deposits). Terminal $B$ forms asymmetric synapses (arrows) with dendrites that likely arise from GCs. Bottom, This labeled axon terminal contains pale mitochondria and spheroidal vesicles and forms asymmetric synapses (arrows) with dendrites of presumed granule cells. Scale bars, $1 \mu \mathrm{m}$. 


\begin{tabular}{|c|c|c|c|c|c|}
\hline & \multirow[b]{3}{*}{ Normal $\mathrm{Cb}$} & \multicolumn{4}{|c|}{ PN-grafted $\mathrm{Cb}$} \\
\hline & & \multicolumn{3}{|c|}{ By distribution of $\mathrm{KGC}$ axons in the $\mathrm{Cb}$} & \multirow[t]{2}{*}{ All animals } \\
\hline & & GCL only & ML only & $\begin{array}{l}\text { GCL and } \\
\text { ML }\end{array}$ & \\
\hline Animals $(n)$ & 4 & 7 & 3 & 8 & $16^{a}$ \\
\hline PN grafts $(n)$ & - & 8 & 3 & 10 & 21 \\
\hline $\mathrm{PC}$ somata $/ 1000 \mu \mathrm{m}^{b}$ & $9.9 \pm 0.3$ & $8.0 \pm 0.5$ & $8.4 \pm 0.7$ & $6.6 \pm 0.8$ & $7.4 \pm 0.4$ \\
\hline
\end{tabular}

"The total number of animals with RGC-Cb grafts in the three distribution groups is 18 instead of 16 because in two of the three animals in the "ML only" group, RGC axons grew into the GCL from a second graft.

${ }^{b}$ Mean \pm SEM.

$P C$ densities and the growth of $R G C$ axons. The possibility that the predilection of RGC axons for the GCL was due to a selective loss of postsynaptic targets in the $\mathrm{ML}$ was investigated by comparing the numbers of PC somata per $1000 \mu \mathrm{m}$ length of PC layer in $3 \mu \mathrm{m}$ sections. PCs were counted both in regions of the $\mathrm{Cb}$ where $\mathrm{RGC}$ axons were observed and in comparable areas of four normal animals (Table 4). There was a $25 \%$ reduction in regional $\mathrm{PC}$ density in the $\mathrm{RGC}$-innervated areas of the $\mathrm{Cb}$ (Table 4), but the distribution of RGC axons within the $\mathrm{Cb}$ did not correlate with PC density (Table 4). Furthermore, in animals in which RGC axons extended into the ML, there was little difference in PC density between those in which RGC axons formed synapses in the ML (three animals; mean, 8.5) and animals in which no synapses were formed (five animals; mean, 7.3). Therefore, a local decrease in the number of PC dendrites in the ML of experimental animals did not appear to be the basis for the predominant innervation of the GCL by RGC axons.

Reactive astrocytes and $R G C$ axon distribution. In the three animals in which the $\mathrm{Cb}$ was processed for GFAP immunoreactivity after the insertion of a $P N$ segment into the vermis, the ends of the PN grafts were surrounded by a zone of GFAP staining with a radius of 100-200 $\mu \mathrm{m}$. No difference in the intensity or extent of GFAP immunoreactivity was detected between the ML and GCL.

\section{Ultrastructure of RGC-Cb terminals}

Several ultrastructural characteristics of the RGC-Cb terminals were similar to those of normal and regenerated RGC terminals in the SC (Huerta and Harting, 1984; Carter et al., 1989, 1991b). In both the $\mathrm{Cb}$ (Fig. 4, bottom; 5, RGC-Cb) and SC, RGC terminals contained spherical vesicles and pale mitochondria and formed asymmetric, axodendritic synapses. However, the average size of RGC terminals in the cerebellar cortex (Table 3) was considerably greater than that of normal or regenerated RGC terminals in the SCs of hamsters studied with similar surgical, labeling, and analytical techniques (Carter et al., 1989; D. A. Carter, G. M. Bray, and A. J. Aguayo, unpublished observations). RGC-Cb terminals had mean areas of $5.6 \pm 0.5$ $\mu \mathrm{m}^{2}$ in the GCL and $7.0 \pm 1.2 \mu \mathrm{m}^{2}$ in the $\mathrm{ML}$ (mean $\pm \mathrm{SEM}$; Table 3). In contrast, the areas were $0.97 \pm 0.02$ and $1.77 \pm$ $0.07 \mu \mathrm{m}^{2}$ for similarly labeled control and regenerated RGCSC terminals, respectively (Carter et al., 1989; Carter, Bray, and Aguayo, unpublished observations). The pcrimcter of RGC terminals in the $\mathrm{Cb}(11.1 \pm 0.8 \mu \mathrm{m}$ in the GCL, $10.5 \pm 1.5 \mu \mathrm{m}$ in the $\mathrm{ML}$; Table 3) was also larger than that of either control $(4.26 \pm 0.06 \mu \mathrm{m})$ or regenerated $(5.7 \pm 0.14 \mu \mathrm{m}) \mathrm{RGC}-\mathrm{SC}$ terminals (Carter et al., 1989; Carter, Bray, and Aguayo, unpublished observations).

The number of synapses $/ 10 \mu \mathrm{m}$ perimeter was similar for RGC-Cb terminals ( $1.5 \pm 0.2$; Table 3 ), control RGC-SC terminals $(1.58 \pm 0.06)$, and regenerated $(1.81 \pm 0.09)$ RGC-SC terminals (Carter et al., 1989; Carter, Bray, and Aguayo, unpublished observations). Due to their larger size, however, RGC$\mathrm{Cb}$ terminals formed, on average, more synaptic contacts per single cross section (mean, 2.0/terminal; Tables 3, 5) than either control $(0.7 /$ terminal) or regenerated (1.0/terminal) RGC-SC terminals (Carter et al., 1989).

There were no significant differences $(p>0.10)$ in terminal areas, perimeters, or synapses $/ 10 \mu \mathrm{m}$ of terminal perimeter between RGC-Cb terminals in the GCL or the ML (Fig. 6; Table 3). Furthermore, the internal structure of RGC-Cb terminals was similar in both locations.

Effect of survival time. Whether using two-way ANOVA or one-way ANOVA with the data pooled for groups A and B, there were no statistically significant changes in the size of the $\mathrm{RGC}-\mathrm{Cb}$ terminals or in the numbers of synapses with increasing survival times after inserting the graft into the $\mathrm{Cb}$ (Table 5, Fig. 6). Moreover, the nonsignificance of the two-way ANOVA test for interaction ( $p$ values $>0.10)$ suggests that the effect of age was similar in both groups.

Effects of denervation. While most RGC terminals and synapses were formed in the GCL in both the group A and B animals (see above and Table 2), the interruption of MF and climbing fiber afferents caused by cutting the middle and inferior cerebellar peduncles (group A) influenced the innervation of the cerebellar cortex in various other ways. In the GCL, the group $A$ animals had twice as many terminals and nearly three times as many synapses as the group B animals (Table 3 ). However, in the three animals in which a total of 12 terminals and 12 synapses were observed in the ML, 11 of the terminals and 10 of the synapses were observed in two hamsters with intact peduncles.

Denervation did not appear to affect the size of $\mathrm{RGC}-\mathrm{Cb}$ terminals; there were no significant differences (all $p$ values $>$ 0.7 ) between the areas or perimeters of the terminals in groups $A$ and $B$ (Tables 3, 5; Fig. 6). The effect of denervation on the numbers of synapses $/ 10 \mu \mathrm{m}$ terminal perimeter was less clearcut. Although some of the $p$ values approached 0.05 (Table 5), there was no consistent tendency for one group to have more synapses than the other; up to 5 months after graft insertion, there were more synapses in the group A animals but at later times this trend seemed to be reversed. Thus, it would be necessary to study more animals to be certain about the effect of 


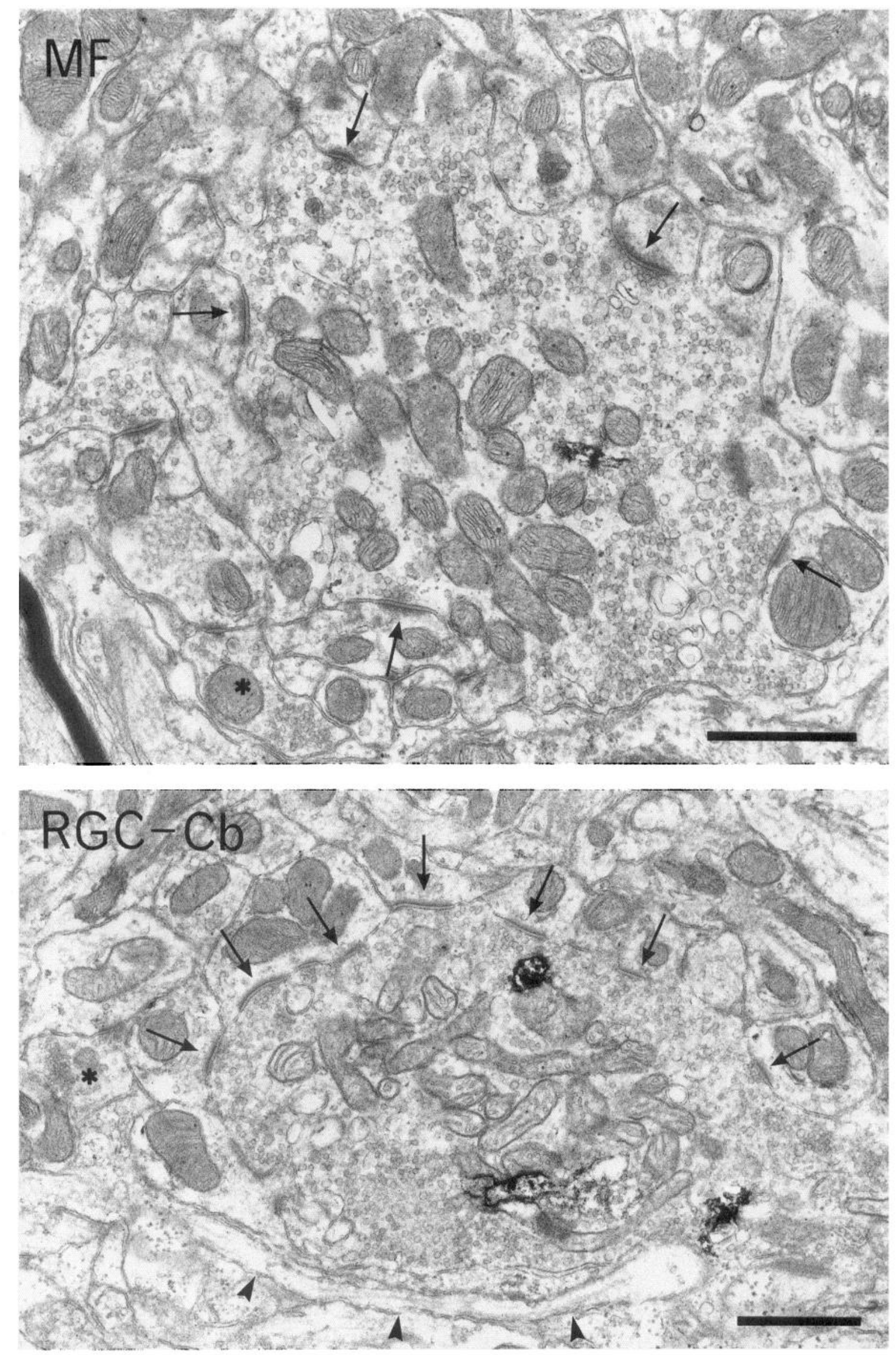


Table 5. RGC axon terminals and synapses in the GCL of the $\mathrm{Cb}$

\begin{tabular}{|c|c|c|c|c|c|c|}
\hline \multirow[b]{2}{*}{ Animal } & \multirow{2}{*}{$\begin{array}{l}\text { Survival time } \\
\text { (months) }\end{array}$} & \multicolumn{3}{|c|}{ Terminals } & \multicolumn{2}{|c|}{ Synapses } \\
\hline & & $n$ & $\begin{array}{l}\text { Areab } \\
\left(\mu \mathrm{m}^{2}\right)\end{array}$ & $\begin{array}{l}\text { Perimeter } \\
(\mu \mathrm{m})\end{array}$ & $n$ & $\begin{array}{l}\text { Per } 10 \mu \mathrm{m} \\
\text { perimeter }\end{array}$ \\
\hline \multicolumn{7}{|c|}{ Group A-ipsilateral middle and inferior cerebellar peduncles transected } \\
\hline 41 & 2 & 7 & $2.3 \pm 1.1$ & $7.1 \pm 1.1$ & 8 & $1.5 \pm 1.5$ \\
\hline 62 & 2 & 25 & $6.7 \pm 5.6$ & $11.6 \pm 6.0$ & 51 & $1.2 \pm 1.5$ \\
\hline 75 & 2 & 18 & $8.3 \pm 6.8$ & $14.6 \pm 7.7$ & 58 & $2.1 \pm 1.4$ \\
\hline 48 & 4 & 17 & $4.6 \pm 3.4$ & $8.7 \pm 3.8$ & 42 & $2.4 \pm 1.9$ \\
\hline 50 & 5 & 4 & $7.4 \pm 6.7$ & $14.5 \pm 7.8$ & 17 & $3.1 \pm 1.8$ \\
\hline 65 & 7 & 52 & $5.2 \pm 4.4$ & $10.3 \pm 5.4$ & 85 & $1.4 \pm 1.6$ \\
\hline Group mean $\pm \mathrm{SEM}$ & & & $5.8 \pm 0.9$ & $11.1 \pm 0.5$ & & $2.0 \pm 0.3$ \\
\hline \multicolumn{7}{|l|}{ Group B-cerebellar peduncles intact } \\
\hline 38 & 2 & 5 & $6.7 \pm 2.5$ & $14.0 \pm 3.0$ & 8 & $1.0 \pm 0.9$ \\
\hline 67 & 2 & 3 & $4.6 \pm 1.9$ & $11.5 \pm 3.9$ & 0 & 0 \\
\hline 53 & 4 & 13 & $4.3 \pm 3.8$ & $8.4 \pm 4.2$ & 10 & $0.8 \pm 1.2$ \\
\hline 77 & 4 & 26 & $6.5 \pm 5.9$ & $10.5 \pm 7.2$ & 49 & $1.1 \pm 1.3$ \\
\hline 64 & 9 & 2 & $6.2 \pm 2.7$ & $13.4 \pm 6.9$ & 7 & $3.2 \pm 2.2$ \\
\hline 80 & 9 & 18 & $3.1 \pm 2.6$ & $8.3 \pm 4.1$ & 18 & $1.3 \pm 1.3$ \\
\hline Group mean \pm SEM & & & $5.4 \pm 0.6$ & $11.0 \pm 1.1$ & & $1.2 \pm 0.5$ \\
\hline \multicolumn{7}{|l|}{$p$ Values } \\
\hline \multicolumn{7}{|l|}{ Group A vs. group B, by survival time } \\
\hline \multirow[t]{3}{*}{ One-way ANOVA } & 2 & & 0.95 & 0.73 & & 0.16 \\
\hline & $4-5$ & & 0.99 & 0.97 & & 0.05 \\
\hline & $7-9$ & & 0.79 & 0.86 & & 0.66 \\
\hline \multicolumn{7}{|l|}{ Group A vs. group B } \\
\hline One-way ANOVA (all times pooled) & & & 0.82 & 0.84 & & 0.07 \\
\hline Two-way ANOVAc & & & 0.88 & 0.80 & & 0.06 \\
\hline \multicolumn{7}{|l|}{ Effect of survival time } \\
\hline One-way ANOVA (A + B pooled) & & & 0.87 & 0.93 & & 0.53 \\
\hline Two-way ANOVA ${ }^{c}$ & & & 0.88 & 0.91 & & 0.24 \\
\hline Interaction: survival time $\times$ lesion & & & 0.99 & 0.96 & & 0.10 \\
\hline
\end{tabular}

${ }^{a}$ Time after insertion of the graft into the cerebellum.

- Mean \pm SEM.

c Factors: 1, survival time; 2, lesion (Group A vs. Group B).

denervation on the numbers of synapses formed by the regenerated RGC axons in the cerebellum.

$R G C-C b$ synapses. Retinal terminals formed synapses with neurons in the cerebellar cortex in 12 (6 in group A, 6 in group B) of the 13 animals examined by EM (Figs. 4; 5, RGC-Cb). A total of 365 RGC-Cb synapses were identified (Tables 3, 5). These synapses were asymmetric and predominantly axodendritic; only one axosomatic synapse was observed. The RGC$\mathrm{Cb}$ terminals formed 353 synapses in the GCL (Table 3 ), in which the postsynaptic structures appeared to be GC dendrites (Figs. 4, bottom; 5, RGC-Cb). One RGC-Cb synapse was on a GC soma, a neuronal domain that normally does not receive synaptic inputs (Palay and Chan-Palay, 1974). In three animals, retinal terminals formed 12 axodendritic synapses in the ML (Table 3). Although the postsynaptic structures were probably PC dendrites, their unequivocal identification was not possible in these animals. The RGC-Cb synapses appear to be persistent because they were found in animals killed up to 9 months after the insertion of the PN graft into the $\mathrm{Cb}$, the longest survival time examined. The longest survival time in which synapses were found in the ML was 4 months.

Comparisons of $R G C-C b$ and normal MF terminals in the $G C L$. In the GCL of normal animals, MF terminals are surrounded by dendrites of GCs and Golgi cell axons (Palay and Chan-Palay, 1974) forming a characteristic glomerulus (Fig. 5, MF). Some of the RGC-Cb terminals in the GCL also appeared to have become part of glomerulus-like complexes; regenerated terminals were surrounded by GC dendrites, with which they formed asymmetric synapses (Figs. 4, bottom; 5, RGC-Cb), and in about one-third of the terminals (62 of 190) Golgi cell-like axons and/or terminals surrounded both the novel retinofugal terminal and its postsynaptic GC dendrites (Fig. 5, RGC-Cb).

Figure 5. Comparison of a normal MF terminal and regenerated RGC-Cb terminal in the GCL. As part of a glomerulus, this MF terminal (top) forms synapses (arrows) with GC dendrites; Golgi cell axon terminals (*) synapse with other GC dendrites. The RGC-Cb terminal (bottom) also forms synapses (arrows) with surrounding dendrites that appear to belong to GCs and is partially surrounded by an axon (arrowheads) and a terminal $\left(^{*}\right)$ of a presumed Golgi cell. The RGC-Cb terminal has pale mitochondria, while the MF terminal contains dark mitochondria. Scale bars, $1 \mu \mathrm{m}$. 

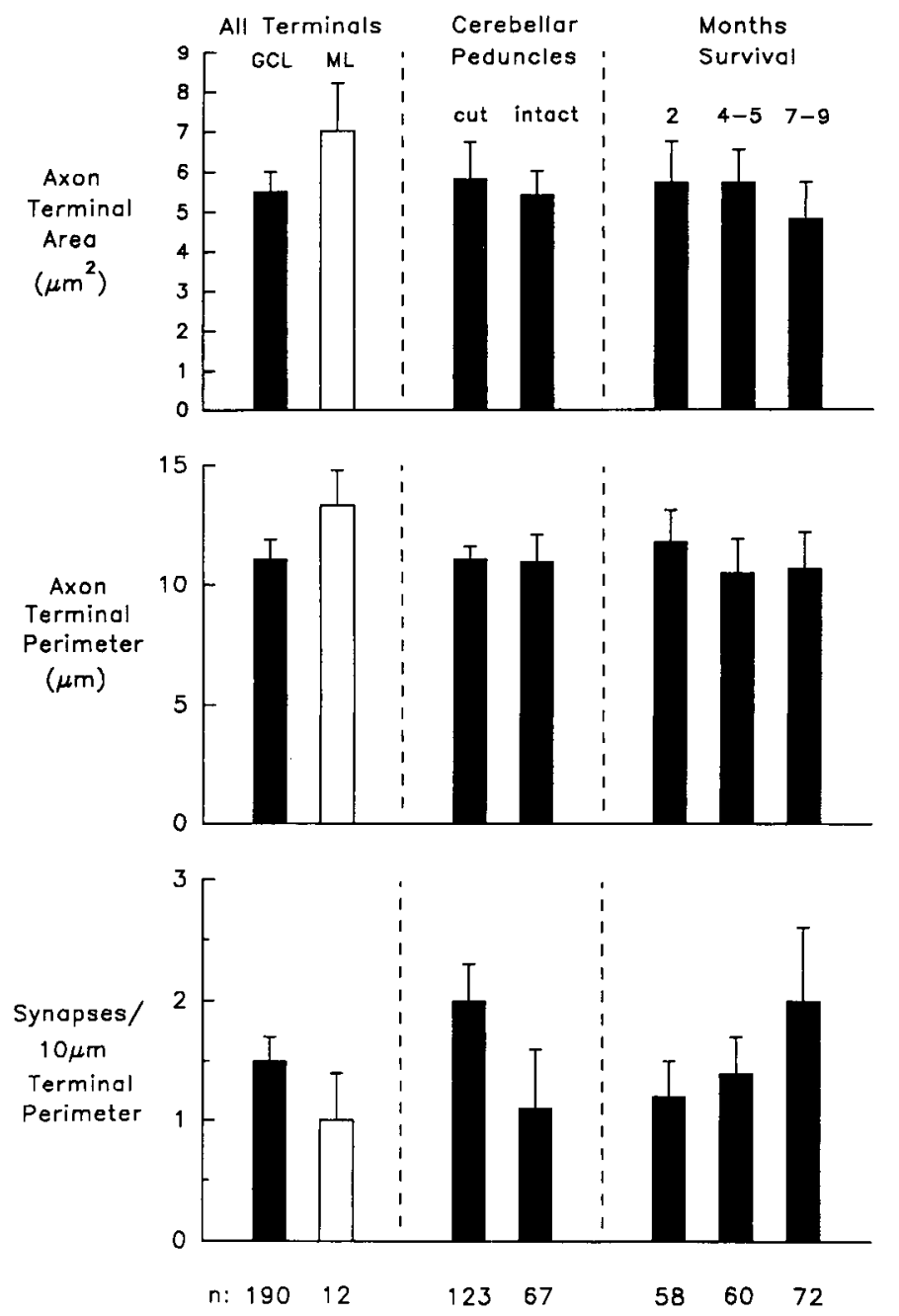

Figure 6. Histograms of the areas, perimeters, and numbers of synapses $/ 10 \mu \mathrm{m}$ terminal perimeter (mean \pm SEM) of regenerated RGC axon terminals in the GCL (solid bars) and ML (open bars) of the Cb. There were no significant differences (ANOVA, $p>0.05$ ) in comparisons of terminals in the GCL and ML (left panels). Within the GCL, neither the area, perimeter, nor synapses $/ 10 \mu \mathrm{m}$ terminal perimeter were significantly influenced $(p>0.3)$ by transection of the cerebellar peduncles (middle panels) or by the duration of survival (right panels). $n$, number of terminals.

It is not known if these glomerulus-like arrangements were a random occurrence or an attempted reconstitution of the glomerulus that is normally present in the GCL.

Neither the mean area $(p>0.1)$ nor the mean perimeter $(p$ $>0.3$ ) of 190 RGC-Cb terminals in the GCL (groups A and B combined) was statistically different from those of $516 \mathrm{MF}$ terminals in the GCL of normal hamsters (Table 3). Furthermore, there was no significant difference $(p>0.2)$ in the number of synapses/ $10 \mu \mathrm{m}$ of perimeter between RGC-Cb and control MF terminals (Table 3 ). The mean area, perimeter, and synapses/ $10 \mu \mathrm{m}$ of perimeter of the $12 \mathrm{RGC}-\mathrm{Cb}$ terminals in the ML were also not significantly different from those of MF terminals. Similar to MFs, the RGC-Cb terminals were filled with clear spherical vesicles and formed asymmetric synapses with $\mathrm{GC}$ dendrites (Fig. 5, Table 3). However, while mitochondria were pale in over $90 \%$ of RGC-Cb terminals in both the GCL and
ML, $97 \%$ of the normal MF terminals contained dark mitochondria (Fig. 5, Table 3). Thus, the staining properties of RGC mitochondria were retained by the retinofugal axons that established persistent connections with cerebellar neurons in the GCL.

\section{Discussion}

When nerve fibers were damaged, the recovery of useful connectivity requires the survival of the injured nerve cells, the regrowth of severed axons toward their normal fields of innervation, and the restoration of synaptic contacts with appropriate targets. Whilc it is now known that several classcs of CNS projection neurons in adult mammals are capable of regenerating their axons over long distances, it is also apparent that conditions in their CNS environment do not permit the lengthy growth required for such axons to reach their distant targets. Therefore, it has been difficult to determine if the reexpression of the neuronal capacities to initiate and sustain axonal elongation can eventually lead to the selective retrieval of their postsynaptic partners and the avoidance of abnormal connections.

\section{The regrowth of $R G C$ axons}

In adult rodents, the substitution of the ON by a long PN graft makes possible the regeneration of $\mathrm{RGC}$ axons into normal or unusual targets that are far removed from the eye. Regenerated $\mathrm{RGC}$ axons guided to one of their normal fields of innervation, the SC, were previously proven to form terminal arborizations and well-differentiated functional synapses within the superficial, retinorecipient layers of the SC (Vidal-Sanz et al., 1987, 1991; Carter et al., 1989, 1991a; Keirstead et al., 1989; Sauvé et al., 1991; Carter, Bray, and Aguayo, unpublished observations). We have now shown that when RGC axons are routed along PN grafts to the $\mathrm{Cb}$, a region of the brain that does not normally receive afferent fibers from the retina, they can also grow into the cerebellar cortex and form synapses. In these animals, the RGC axons that had elongated more than $2 \mathrm{~cm}$ along the PN grafts penetrated the $\mathrm{Cb}$ for up to $650 \mu \mathrm{m}$, an extension into the CNS that approximates that of the RGC axons that regenerate into the SC (Carter et al., 1989, 199 la; Carter, Bray, and Aguayo, unpublished observations). The regenerating RGC axons grew predominantly into the cerebellar cortex, while extension into the white matter was exceptional and only for up to $50 \mu \mathrm{m}$. This limited growth into the white matter is consistent with other studies that suggest that myclin components in the CNS of adult mammals inhibit cell adhesion and neurite outgrowth in vitro (Caroni and Schwab, 1988) and may block axonal extension in vivo (Schnell and Schwab, 1990).

The growth of the $\mathrm{RGC}$ axons into the $\mathrm{Cb}$ was more extensive in the animals in which the cerebellar peduncles had been transected (group A) than in those with intact peduncles (group B). The 1.5-fold greater penetration of axons from the end of the grafts, the formation of nearly twice as many RGC-Cb terminals, and a three-fold increase in the number of synapses were signs of this effect of denervation. Such enhancement in axonal ingrowth and synaptogenesis could reflect a greater availability of synaptic sites in the cerebellar cortex of the lesioned animals. Furthermore, an increased expression of molecules that facilitate axonal growth has been reported after CNS denervation (Needels et al., 1986). While the expression of such factors has not been investigated in the lesioned $\mathrm{Cb}$, it is known that interruption of the cerebellar peduncles (Pickel et al., 1973) or 
partial destruction of nuclei that project fibers to the $\mathrm{Cb}$ (Rossi et al., 1989) can result in axonal sprouting and a more prominent arborization of intact cerebellar afferents.

\section{Morphology of $\mathrm{RGC}-\mathrm{Cb}$ terminals}

The novel RGC-Cb terminals were significantly larger and established more synapses per terminal than the regenerated RGC terminals in the SC (Carter et al., 1989; Carter, Bray, and Aguayo, unpublished observations). Others have also observed the formation of larger terminals by regenerating (Radel and Yoon, 1985; Carter et al., 1989; Itoh and Tessler, 1990b; Carter, Bray, and Aguayo, unpublished observations) or sprouting axons (Raisman, 1969; Chen and Hillman, 1982; Steward et al., 1988). In goldfish (Radel and Yoon, 1985) and hamsters (Carter et al., 1989; Carter, Bray, and Aguayo, unpublished observations) regenerated RGC-SC terminals are initially larger than controls but become smaller with time. In rats, regenerated RGC terminals in the $\mathrm{SC}$, analyzed 18 months after joining the eye and the $\mathrm{SC}$ with a PN graft, showed no significant differences in size from age-matched controls (Vidal-Sanz et al., 1991). It is therefore puzzling that the size of the regenerated retinal terminals formed in the $\mathrm{Cb}$ did not decrease significantly over the 7 months spanned by the present study in hamsters.

Because the size of the RGC terminals in the GCL approximated that of normal MF afferents to the GCL, it could be postulated that this layer of the $\mathrm{Cb}$ had a specific influence on the morphology of these novel terminals. Neuroanatomical investigations of connections in the developing and mature CNS provide evidence that the target can indecd influcnce the shape and size of terminals (Ramon y Cajal, 1911; Morest, 1968; Lund, 1969; Mugnaini, 1970; Mason and Gregory, 1984). Furthermore, the terminal morphology of retinal axons that form connections with nonretinal targets in immature rodents more closely resembles that of the normal afferents to such targets (Kalil and Schneider, 1975; Campbell and Frost, 1988). However, large RGC terminals were also found in the ML of our experimental animals. In addition, in studies in adult hamsters where RGC axons were guided along PN grafts into other regions of the brain that normally do not receive direct retinal inputs (e.g., the central nucleus of the inferior colliculus or the visual and somatosensory cortices; Zwimpfer et al., 1990), synapses were also formed. In the inferior colliculus of these animals, the size of regenerated $\mathrm{RGC}$ terminals was also significantly larger than regenerated $\mathrm{RGC}$ terminals in the $\mathrm{SC}$ for up to 8 months (T. J. Zwimpfer, A. J. Aguayo, and G. M. Bray, unpublished observations). The persistence of large RGC axon terminals in these various parts of the CNS may be related to their aberrant location.

For the regenerated RGC-Cb axons, the number of synapses per $10 \mu \mathrm{m}$ of terminal perimeter (1.5) was similar to that determined previously for regenerated (1.8) or normal (1.6) RGC terminals in the SC (Carter et al., 1989; Carter, Bray, and Aguayo, unpublished observations). One interpretation of these consistent relationships between the size of the terminals and the number of synapses formed is that the frequency of contacts influences the size of the terminals. Conversely, the formation of larger terminals, with their more abundant surface areas, might have made possible the establishment of a greater number of contacts. In either case, it can be assumed that interactions with postsynaptic elements capable of influencing the formation and turnover of the axonal membrane (Liuzzi and Lasek, 1987; Liuzzi, 1990) ultimately determines the size of these and other terminals. The recent finding of a higher-than-normal density of terminals in the arbors made by some regenerated RGC axons that reinnervate the $\mathrm{SC}$ of adult hamsters might also denote a tendency of these growing fibers to form synapses soon after they penetrate their CNS targets (Carter, Bray, and Aguayo, unpublished observations). It is not known, however, if these changes are due to a greater propensity for synaptogenesis by regenerating as opposed to developing $\mathrm{CNS}$ axons or if adhesive interactions between growing axons and their substrates (Monard, 1988) affect the extension of axons in these CNS regions.

\section{The preference of $R G C$ axons for the $G C L$}

Within the gray matter, RGC axons did not appcar to cxtcnd or synapse randomly but displayed a predilection for the GCL; RGCs innervated the GCL in all but 1 of the 17 hamsters studied, and in 14 of these animals the growth was predominantly or exclusively in the GCL. Moreover, $95 \%$ of RGC-Cb terminals and synapses were located in this layer. In goldfish, in which regenerating $\mathrm{RGC}$ axons grew into the $\mathrm{Cb}$ after unilateral (Lo and Levine, 1980) or bilateral (Sharma, 1981) tectal ablations, the axons also extended selectively into the GCL (Lo and Levine, 1980).

The apparent predilection of retinal terminals for the GCL could have been due to a retraction of axons from the ML after an initial, less specific deployment. Indeed, withdrawal of retinal axons or axon collaterals is thought to contribute to the refinement of retinofugal connections during development (Kalil et al., 1986; O'Leary, 1987; Sretavan et al., 1988; Nakamura and O'Lcary, 1989; Thompson and Holt, 1989; Bhide and Frost, 1991), and in regeneration of retinotectal axons in the goldfish (Meyer et al., 1985; Rankin and Cook, 1986; Stuermer, 1988) and frog (Reh and Constantine-Paton, 1985). While the preferential innervation of the GCL in the adult hamsters was already detectable at the shortest survival time studied ( 2 months), an earlier scrutiny would be needed to verify that the initial orientation of regenerated $\mathrm{RGC}$ axons entering the $\mathrm{Cb}$ was indeed toward the GCL.

Avoidance of the ML might also have influenced RGC axons to grow preferentially within the GCL. Although in vitro studies of both chick (Walter et al., 1987a,b, 1990; Cox et al., 1990; Stahl et al., 1990) and goldfish (Vielmetter and Stuermer, 1989) retinotectal preparations have shown that the rostrocaudal arrangement of $\mathrm{RGC}$ axons in the tectum may be partly determined by inhibitory influences, there is no indication that such inhibitory molecules also influcnec the laminar deployment of retinal axons in the SC. Furthermore, a blocking of axonal regrowth by components of CNS myelin (Caroni and Schwab, 1988; Schnell and Schwab, 1990) is unlikely to account for the distinct distribution of the regenerated RGC-Cb connections to the GCL because this layer contains more myelinated fibers than the ML (Palay and Chan-Palay, 1974). Moreover, the demonstration that intact climbing fibers can sprout within the ML of the adult rat (Rossi et al., 1989) suggests that the ML is not a barrier to axonal extension within the cerebellar cortex.

During development, the migration of neurons and the distribution of axonal projections in the CNS may be influenced by molecular boundaries (Keynes and Lumsden, 1990; Snow et al., 1990). If there were a comparable barrier in adult rodents between the GCL and the ML, the extension of RGC axons across the PC layer could be curtailed. Such a putative boundary might also clarify why PCs transplanted into the cerebellar cortex of PC degeneration mutant mice tend not to project beyond 
the GCL-ML border (Sotelo et al., 1990; Sotelo and AlvaradoMallart, 1991). However, this mechanism would not explain why most axons arising from PN grafts positioned at the MLGCL border tended to grow into the GCL. Although reactive astrocytes might act as a barrier (Liuzzi and Lasek, 1987; Fawcett et al., 1989) that prevented the RGC axons from entering the ML or as a substrate that facilitated axon growth (David et al., 1990; Hall et al., 1991) into the GCL, the distribution of these cells, assessed by GFAP immunoreactivity, was similar in the ML and GCL.

Finally, the scarcity of $\mathrm{RGC}$ axonal extension into the $\mathrm{ML}$ did not seem to be due to a selective loss of postsynaptic targets in the ML caused by $\mathrm{Cb}$ damage during graft insertion. Compared to the normal $\mathrm{Cb}$, the mean density of PC somata in the region of the cerebellar cortex surrounding the graft was decreased by only $25 \%$ and PC density did not differ between animals with or without RGC innervation of the ML.

\section{Role of denervation of the distribution of $R G C-C b$ connections}

Denervation influences the distribution of connections formed by axonal sprouts. In the adult mammalian CNS, the loss of afferent connections induces uninjured axons to sprout collaterals that grow selectively into the denervated regions (Raisman, 1969, 1985; Cotman et al., 1981; Rossi et al., 1989). However, within the narrow range covered by their growth, the sprouting axons appear to contact their normal targets preferentially even if other adjacent nerve cells are also denervated (Raisman, 1985). Furthermore, fetal neurons transplanted into the brains of neonatal (Hankin and Lund, 1987) or adult (Gage ct al., 1985) rats tended to extend axons selectively into nearby groups of host neurons that are their normal targets and avoid denervated regions that do not receive afferents from the type of cells contained in the graft.

In the group A hamsters of the present study, interruption of both MF and climbing fiber afferents caused by transecting the cerebellar peduncles would have affected neurons in both the GCL and ML. However, neurons in the GCL would be more extensively denervated than the PCs because parallel fiber inputs to the ML would be preserved (Palay and Chan-Palay, 1974). It is also important to recognize that in hamsters with intact or cut cerebellar peduncles, cells and axons are locally damaged by the insertion of the PN grafts. The distribution of such local damage would depend on the location of the PN grafts. With grafts in the GCL, some climbing and parallel fiber afferents to the ML and MF inputs to the GCL would be interrupted, denervating both the GCL and ML. However, the grafts located at or near the GCL-ML border would have denervated the ML more extensively by interrupting the climbing and parallel fiber inputs. Despite these three possible patterns of denervation within the $\mathrm{Cb}$ (GCL > ML, GCL = ML, and ML > GCL), RGC axons predominantly or exclusively innervated the GCL in 14 of the 17 experimental animals.

\section{Synaptogenesis with abnormal targets}

Because neither the morphological features of the $\mathrm{Cb}$ nor the conditions related to the experimental procedure discussed above appear to explain the preference of RGC axons to extend and synapse in the GCL of the $\mathrm{Cb}$, it is necessary to consider the possibility that the $\mathrm{RGC}$ axons may select the GCL because it expresses critical molecular constituents that are similar or identical to those present in their normal targets. Certain molccules, which are highly expressed in both the SC and the GCL of the
$\mathrm{Cb}$, are potential candidates for such a role; these may include brain-derived neurotrophic factor (BDNF) (Hofer et al., 1990), a protein known to influence RGC growth and survival (Johnson et al., 1986; Thanos et al., 1989), and the NMDA subtype of glutamate receptor (Cline and Constantine-Paton, 1989; Debski et al., 1990).

In vivo examples of the role of trophic factors in the guided growth and maintenance of connections include the anomalous invasion of peripheral sympathetic fibers into regions of the brainstem injected with NGF (Levi-Montalcini, 1976; Crutcher, 1987) and the extension of septohippocampal axons toward exogenous sources of NGF within the brain (Hagg et al., 1990) or into regions of increased NGF synthesis in the denervated hippocampus (Crutcher and Collins, 1986; Crutcher, 1987). Furthermore, in vitro, neurites from chick dorsal root ganglia are known to grow toward high concentrations of NGF (Gundersen and Barrett, 1979). However, such effects have not yet been investigated for BDNF or other NGF-related neurotrophins.

Neurotransmitter-receptor interactions are thought to influence the formation of normal (Cohen et al., 1987) and anomalous (Landmesser, 1972; Schotzinger and Landis, 1990) connections in the PNS. In rat RGCs, $N$-acetylaspartylglutamate is a putative neurotransmitter (Anderson et al., 1987; Tsai et al., 1990) that can activate the NMDA subtype of glutamate receptor (Westerbrook et al., 1986; Sekiguchi et al., 1987). The NMDA receptor is present in the $\mathrm{SC}$ of the adult rat, especially in the superficial layers (Monaghan and Cotman, 1985) and, in the cat, has been shown to mediate postsynaptic responses in the retinogeniculate pathway (Kemp and Sillito, 1982). Mossy, climbing, and parallel fiber inputs to the $\mathrm{Cb}$ of adult rodents all appear to be glutaminergic (Foster and Roberts, 1983; Freeman et al., 1983), but the NMDA subtype is the predominant glutamate receptor in the GCL (Monaghan and Cotman, 1985; Olson et al., 1987). Furthermore, studies in the visual system of the frog suggest that the refinement of retinotectal connections may involve NMDA receptor activation (Cline et al., 1987; Cline and Constantine-Paton, 1989; Debski et al., 1990).

While the molecular determinants of interneuronal recognition and connectivity have not been elucidated, various experimental combinations of regenerating axons and target cells have demonstrated that unusual connections can be established in the PNS (Close, 1965; Landmesser, 1972; Bixby and Van Essen, 1979; McMahon and Wall, 1989; Schotzinger and Landis, 1990; for revicw, scc Purves and Lichtman, 1985) and also in the CNS of the adult frog (Cantore and Scalia, 1987; Scalia, 1987) and goldfish (Yoon, 1971; Schmidt, 1978; Meyer, 1979; Sharma, 1981), as well as in the CNS of immature mammals (Kalil and Schneider, 1975; Frost, 1981; Campbell and Frost, 1988; Sur et al., 1988). In addition, both normal and abnormal connections have been demonstrated following transplantation of fetal neurons into the brains of adult mammals (McLoon and Lund, 1983; Nilsson et al., 1988; Clarke et al., 1990; Itoh and Tessler, 1990a).

In the damaged CNS, the formation of such aberrant connections might influence recovery in several ways. Premature synaptogenesis near the site of injury could curtail further axonal extension (Bernstein and Bernstein, 1971) or create new circuits (Sur et al., 1988; Métin and Frost, 1989; Roe et al., 1990) that can generate maladaptive behaviors (Schneider, 1973; Easter and Schmidt, 1977). On the other hand, novcl connections might also help establish alternate pathways (Métin and Frost, 1989; 
Roe et al., 1990) that compensate for lost or impaired functions. The existence of potential synaptic interactions in regions of the nervous system that normally have no anatomical or functional connections underscores the importance of the mechanisms that guide the long-range growth of axons to the proximity of their normal fields of innervation (Lumsden and Davies, 1986; Dodd and Jessell, 1988; Tessier-Lavigne et al., 1988; Harris, 1989; Godement et al., 1990). While advances have been made in promoting neuronal survival, axonal regrowth, and synaptogenesis, limitations in such long-range guidance in the mature CNS may continue to impose critical constraints on the recovery of useful connectivity in the injured mammalian nervous system. However, the apparent expression in the CNS of these animals of certain growth and synaptic preferences within the narrow field encompassed by terminal axonal arborizations also raises the possibility that appropriate connections may be restored spontaneously by guiding regenerating axons to the vicinity of their normal fields of innervation, or by enhancing the short-range extension of fibers interrupted near their targets.

\section{References}

Aguayo AJ, Carter DA, Zwimpfer TJ, Vidal-Sanz M, Bray GM (1990) Axonal regeneration and synapse formation in the injured CNS of adult mammals. In: Brain repair (Björklund A, Aguayo AJ, Ottoson D, eds), pp 251-272. London: Macmillan.

Anderson KJ, Borja MA, Cotman CW, Moffett JR, Namboodiri MAA, Neale JH (1987) $N$-acetylaspartylglutamate identified in the rat retinal ganglion cell and their projections in the brain. Brain Res 411: 172-177.

Bernstein JJ, Bernstein ME (1971) Axonal regeneration and formation of synapses proximal to the site of lesion following hemisection of the rat spinal cord. Exp Neurol 30:336-351.

Bhide PG, Frost DO (1991) Stages of growth of hamster retinofugal axons: implications for developing axonal pathways with multiple targets. J Neurosci 11:485-504.

Bignami A, Dahl D (1976) The astroglial response to stabbing. Immunofluorescence studies with antibodies to astrocyte-specific protein (GFA) in mammalian and submammalial vertebrates. Neuropathol Appl Neurobiol 2:99-110.

Bixby JL, Van Essen DC (1979) Competition between foreign and original nerves in adult mammalian skeletal muscle. Nature 282:726728.

Campbell G, Frost DO (1988) Synaptic organization of anomalous retinal projections to the somatosensory and auditory thalamus: target controlled morphogenesis of axon terminals and synaptic glomeruli. J Comp Neurol 272:383-408.

Cantore WA, Scalia F (1987) Ultrastructural evidence of the formation of synapses by retinal ganglion cell axons in two non-standard targets. J Comp Neurol 261:137-147.

Caroni P, Schwab ME (1988) Two membrane protein fractions from rat central myelin with inhibitory properties for neurite growth and fibroblast spreading. J Cell Biol 106:1281-1288.

Carter DA, Bray GM, Aguayo AJ (1989) Regenerated retinal ganglion cell axons can form well-differentiated retinal ganglion cell axons in the superior colliculus of adult hamsters. J Neurusci 9:4042-4050.

Carter DA, Bray GM, Aguayo AJ (1991a) Patterns of the arborizations made by retinal ganglion cell axons regenerating into the superior colliculus of adult hamsters. Soc Neurosci Abstr 17:568.

Carter DA, Aguayo AJ, Bray GM (1991b) Retinal ganglion cell terminals in the hamster superior colliculus: an ultrastructural study. $\mathbf{J}$ Comp Neurol 311:97-107.

Chen S, Hillman DE (1982) Plasticity of the parallel fiber-Purkinje cell synapse by spine takeover and new synapse formation in the adult rat. Brain Res 240:205-220.

Clarke DJ, Nilsson OG, Brundin P, Björklund A (1990) Synaptic connections formed by grafts of different types of cholincrgic ncurons in the host hippocampus. Exp Neurol 107:11-22.

Cline HT, Constantine-Paton M (1989) NMDA receptor antagonists disrupt the retinotectal topographic map. Neuron 3:413-426.

Cline HT, Debski EA, Constantine-Paton M (1987) NMDA receptor antagonist desegregates eye-specific stripes. Proc Natl Acad Sci USA 84:4342-4345.

Close R (1965) Effects of cross-union of motor nerves to fast and slow skeletal muscles. Nature 206:831-832.

Cohen MW, Rodriguez-Marin E, Wilson EM (1987) Distribution of synaptic specializations along isolated motor units formed in Xenopus nerve-muscle cultures. J Neurosci 7:2849-2861.

Cotman CW, Nieto-Sampedro M, Harris EW (1981) Synapse replacement in the nervous system of adult vertebrates. Physiol Rev 61:684784.

Cox EC, Müller B, Bonhoeffer F (1990) Axonal guidance in the chick visual system: posterior tectal membranes induce collapse of growth cones from the temporal regina. Neuron 4:31-37.

Crutcher KA (1987) Sympathetic sprouting in the central nervous system: a model for studies of axonal growth in the mature mammalian brain. Brain Res Rev 12:203-233.

Crutcher KA, Collins F (1986) Entorhinal lesions result in increased nerve growth factor-like growth-promoting activity in medium conditioned by hippocampal slices. Brain Res 399:383-389.

David S, Boucher C, Tsatas O, Giftochristos N (1990) Macrophages can modify the nonpermissive nature of the adult mammalian central nervous system. Neuron 5:463-469.

Debski EA, Cline HT, Constantine-Paton M (1990) Activity-dependent tuning and the NMDA receptor. J Neurobiol 21:18-32.

Dodd J, Jessell TM (1988) Axon guidance and the patterning of neuronal projections in vertebrates. Science $21: 18-32$.

Easter SS, Schmidt JT (1877) Reversed visuomotor behaviour mediated by induced ipsilateral retinal projections in goldfish. $J$ Neurophysiology 40:1245-1254.

Fawcett JW, Housden E, Smith-Thomas L, Meyer RL (1989) The growth of axons in three-dimensional astrocyte cultures. Dev Biol 135:449-458.

Foster GA, Roberts PJ (1983) Neurochemical and pharmacological correlates of inferior olive destruction in the rat: attenuation of the events mediated by an endogenous glutamate-like substance. Neuroscience 8:277-284.

Freeman ME, Lane JD, Smith JE (1983) Turnover rates of amino acid neurotransmitters in regions of rat cerebellum. J Neurochem 40:14411447.

Frost DO (1981) Orderly anomalous retinal projections to the medial geniculate, ventrobasal and lateral posterior nuclei of the hamster. J Comp Neurol 203:227-256.

Frost DO (1984) Axonal growth and target selection during development: retinal projections to the ventrobasal complex and other "nonvisual" structures in neonatal Syrian hamsters. J Comp Neurol 230:576-592.

Gage FH, Björklund A, Steveni U, Dunnett SB (1985) Grafting of embryonic CNS tissue to the damaged adult hippocampal formation. In: Neural grafting in the mammalian CNS (Björklund A, Stenevi U, eds), pp 559-573. New York: Elsevier.

Godement P, Salaun J, Mason CA (1990) Retinal axon pathfinding in the optic chiasm: divergence of crossed and uncrossed fibers. Neuron 5:173-186.

Gundersen RW, Barrett IN (1979) Neuronal chemotaxis: chick dorsalroot axons turn toward high concentrations of nerve growth factor. Science 206:1079-1080.

Hagg T, Vahlsing HL, Manthorpe M, Varon S (1990) Nerve growth factor infusion into the denervated adult rat hippocampal formation promotes its cholinergic reinnervation. J Neurosci 10:3087-3092.

Hall S, Gregson N, Rickard S (1991) Interaction of regrowing PNS axons with transplanted aggregates of cultures CNS glia in vivo. $\mathrm{J}$ Neurocytol 20:299-309.

Hankin MH, Lund RD (1987) Role of the target in directing the outgrowth of retinal axons: transplants reveal surface-related and surface-independent cues. J Comp Neurol 263:455-466.

Harris WA (1989) Local positional cues in the neuroepithelium guide retinal axons in embryonic Xenopus brain. Nature 339:218-221.

Hofer M, Pagliusi SR, Hohn A, Leibrock J, Barde Y-A (1990) Regional distribution of brain-derived neurotrophic factor $\mathrm{mRNA}$ in the adult mouse brain. EMBO J 9:2459-2464.

Huerta MF, Harting JK (1984) The mammalian supcrior colliculus: studies of its morphology and connections. In: Comparative neurology of the optic tectum (Vanegas H, ed), pp 687-773. New York: Plenum.

Itoh Y, Tessler A (1990a) Ultrastructural organization of regenerated 
adult dorsal root axons within transplants of fetal spinal cord. J Comp Neurol 292:396-411.

Itoh I, Tessler A (1990b) Regeneration of adult dorsal root axons into transplants of fetal spinal cord and brain: a comparison of growth and synapse formation in appropriate and inappropriate targets. $J$ Comp Neurol 302:272-293.

Johnson JE, Barde Y-A, Schwab M, Thoenen H (1986) Brain-derived neurotrophic factor supports the survival of cultured rat retinal ganglion cells. J Neurosci 6:3031-3038.

Kalil RE, Schneider GE (1975) Abnormal synaptic connections of the optic tract in the thalamus after midbrain lesions in newborn hamsters. Brain Res 100:690-698.

Kalil RE, Dubin MW, Scott G, Stark LA (1986) Elimination of action potentials blocks the structural development of retinogeniculate synapses. Nature 323:156-158.

Keirstead SA, Rasminsky M, Fukuda Y, Carter DA, Aguayo AJ, VidalSanz M (1989) Electrophysiologic responses in hamster superior colliculus evoked by regenerating retinal axons. Science 246:255-258.

Kemp JA, Sillito AM (1982) The nature of the excitatory transmitter mediation $\mathrm{X}$ and $\mathrm{Y}$ cell inputs to the cat dorsal lateral geniculate nucleus. J Physiol (Lond) 323:377-391.

Keynes R, Lumsden A (1990) Segmentation and the origin of regional diversity in the vertebrate nervous system. Neuron 4:1-9.

Landmesser L (1972) Pharmacological properties, cholinesterase activity and anatomy of nerve-muscle junction in vagus-innervated frog sartorius. J Physiol (Lond) 220:243-256.

Larsell O (1952) The morphogenesis and adult pattern of the lobules and fissures of the cerebellum of the white rat. J Comp Neurol 97: 281-356.

Lemann W, Saper CB, Rye DB, Wainer BH (1985) Stabilization of TMB reaction product for electron microscopic retrograde and anterograde fiber tracing. Brain Res Bull 14:277-281.

Levi-Montalcini (1976) The nerve growth factor: its role in growth, differentiation and function of the sympathetic adrenergic neuron. Prog Brain Res 45:235-258.

Liuzzi FJ (1990) Proteolysis is a critical step in the physiological stop pathway: mechanisms involved in the blockade of axonal regeneration hy mammalian astrocytes. Brain Res 512:277-283.

Liuzzi FJ, Lasek RJ (1987) Astrocytes block axonal regeneration in mammals by activating the physiological stop pathway. Science 237 : 642-645.

Lo RYS, Levine R (1980) Time course and pattern of optic fiber regeneration following tectal lobe removal in the goldfish. J Comp Neurol 191:295-314.

Lumsden AGS, Davies AM (1986) Chemotropic effect of specific target epithelium in the developing mammalian nervous system. Nature 323:538-539.

Lund RD (1969) Synaptic patterns of the superficial layers of the superior colliculus of the rat. J Comp Neurol 135:197-208.

Mason CA, Gregory E (1984) Postnatal maturation of cerebellar mossy and climbing fibers: transient expression of dual features on single axons. J Neurosci 4:1715-1735.

McLoon SC, Lund RD (1983) Development of fetal retina, tectum and cortex transplanted to the superior colliculus of adult rats. J Comp Neurol 217:376-389.

McMahon SB, Wall P (1989) Changes in spinal cord reflexes after cross-anastomosis of cutaneous and muscle nerves in the adult rat. Nature 342:272-274.

Métin C, Frost DO (1989) Visual responses of neurons in somatosensory cortex of hamsters with experimentally induced retinal projections to somatosensory thalamus. Proc Natl Acad Sci USA 86:357361.

Meyer RL (1979) Retinotectal projection in goldfish to an inappropriate region with a reversal in polarity. Science 205:819-821.

Meyer RL, Sakurai K, Schauwecker E (1985) Topography of regenerating optic fibers in goldfish traced with local wheat germ injections into retina: evidence for discontinuous microtopography in the retinotectal projection. J Comp Neurol 239:27-43.

Monaghan DT, Cotman CW (1985) Distribution of $N$-mcthyl-D-aspartate-sensitive $\mathrm{L}-\left[{ }^{3} \mathrm{H}\right]$ glutamate-binding sites in rat brain. J Neurosci 5:2909-2919.

Monard D (1988) Cell-derived proteases and protease inhibitors as regulators of neurite outgrowth. Trends Neurosci 11:541-544.

Morest DK (1968) The collateral system of the medial nucleus of the trapezoid body of the cat, its neuronal architecture and relation to the olivo-cochlear bundle. Brain Res 9:288-311.
Mugnaini E (1970) Neurones as synaptic targets. In: Excitatory synaptic mechanisms (Anderson P, Jansen JKS, eds), pp 149-169. Oslo: Universitetsforlaget.

Nakamura H, O'Leary DDM (1989) Inaccuracies in initial growth and arborization of chick retinotectal axons followed by course corrections and axon remodelling to develop topographic order. J Neurosci 9: 3776-3795.

Needels DL, Nieto-Sampedro M, Cotman CW (1986) Induction of a neurite-promoting factor in rat brain following injury or deafferentiation. Neuroscience 18:517-526.

Nilsson OG, Clarke DH, Brundin P, Björklund A (1988) Comparison of growth and reinnervation properties of cholinergic neurons from different brain regions grafted to the hippocampus. J Comp Neurol 268:204-222

O'Leary DDM (1987) Remodelling of early axonal projections through the selective eliminaton of neurons and long axon collaterals. In: Selective neuronal death (Bock G, O'Connor M, eds), pp 113-142. Chichester: Wiley.

Olson JMM, Greenamyre JT, Penney JB, Young AB (1987) Autoradiographic localization of cerebellar excitatory amino acid binding sites in the mouse. Neuroscience 22:913-923.

Palay SL, Chan-Palay V (1974) Cerebellar cortex, pp 1-287. New York: Springer.

Pickel VM, Krebs H, Bloom FE (1973) Proliferation of norepinephrine-containing axons in rat cerebellar cortex after peduncle lesions. Brain Res 59:169-179.

Purves D, Lichtman I (1985) Principles of neural development, pp 229-270. Sunderland, MA: Sinauer.

Radel JD, Yoon MG (1985) Time-course of ultrastructural changes in the regenerated optic fiber terminals of goldfish. Brain Res 342 : $168-171$.

Raisman G (1969) Neuronal plasticity in the septal nuclei of the adult rat. Brain Res 14:25-48.

Raisman G (1985) Synapse formation in the septal nuclei of adult rats. In: Synaptic plasticity (Cotman CW, ed), pp 13-38. New York: Guilford.

Ramon y Cajal S (1911) Histologie du système nerveux de l'homme et des vertébrés, vol 1. Paris: A. Maloine [reprint (1955), pp 754 838. Madrid: Consejo Superior de Investigaciones Cientificas, Institut Ramon y Cajal].

Rankin ECC, Cook JE (1986) Topographic refinement of the regenerating retinotectal projection of the goldfish in standard laboratory conditions: a quantitative WGA-HRP study. Exp Brain Res 63:409420.

Reh TA, Constantine-Paton M (1985) Eye-specific segregation requires neural activity in three-eyed Rana pipiens. J Neurosci 5:11321143.

Roe AW, Pallas SL, Hahm J, Sur M (1990) A map of visual space induced in primary auditory cortex. Science 250:818-820.

Rossi F, Wiklund L, van der Want JJL, Strata P (1989) Climbing fibre plasticity in the cerebellum of the adult rat. Eur J Neurosci 1:543547.

Sauvé Y, Rasminsky M, Carter DA (1991) Distribution and characterization of responses to light in reinnervated hamster superior colliculus. Soc Neurosci $\Lambda$ bstr 17:568.

Scalia F (1987) Synapse formation in the olfactory cortex by regenerating optic axons: ultrastructural evidence for polyspecific chemoaffinity. J Comp Neurol 263:497-513.

Schmidt JT (1978) Retinal fibers alter tectal positional markers during the expansion of the half retinal projection in goldfish. J Comp Neurol 177:279-300.

Schneider GE (1973) Early lesions of superior colliculus: factors affecting the formation of abnormal retinal projections. Brain Behav Evol 8:73-109.

Schnell L, Schwab ME (1990) Axonal regeneration in the rat spinal cord produced by an antibody against myelin-associated neurite growth inhibitors. Nature 343:269-272.

Schotzinger RJ, Landis SC (1990) Acquisition of cholinergic and peptidergic properties of sympathetic innervation of rat sweat glands requires interaction with normal target. Neuron 5:91-100.

Sekiguchi M, Okamato K, Sakai Y (1987) Excitatory action of $N$-acetylaspartylglutamate on Purkinje cells in guinea pig cerebellar slices: an intrasomatic study. Brain Res 423:23-33.

Sharma SC (1981) Retinal projection in a non-visual area after bilateral tectal ablation in goldfish. Nature 291:66-67.

Snow DM, Steindler DA, Silver J (1990) Molecular and cellular char- 
acterization of the glial roof plate of the spinal cord and optic tectum: a possible role for a protcoglycan in the devclopment of an axon barrier. Dev Biol 138:359-376.

Sotelo C, Alvarado-Mallart RM (1991) The reconstruction of cerebellar circuits. Trends Neurosci 14:350-355.

Sotelo C, Alvarado-Mallart RM, Gardette R, Crepel F (1990) Fate of grafted embryonic Purkinje cells in the cerebellum of the adult "Purkinje cell degeneration" mutant mouse. I. Development of reciprocal graft-host interactions. J Comp Neurol 295:165-187.

Sretavan DW, Shatz CJ, Styker MP (1988) Modification of retinal ganglion cell axon morphology by prenatal infusion of tetrodotoxin. Nature 336:468-471.

Stahl B, Muller B, von Boxberg Y, Cox EC, Bonhoeffer F (1990) Biochemical characterization of a putative axonal guidance molecule of the chick visual system. Neuron 5:735-743.

Steward O, Vinsant SL, Davis L (1988) The process of reinnervation in the dentate gyrus of adult rats: an ultrastructural study of changes in presynaptic terminals as a result of sprouting. J Comp Neurol 267: 203-210.

Stuermer CAO (1988) Trajectories of regenerating retinal axons in the tectum: I. A comparison of normal and regenerated axons at late regeneration stages. J Comp Neurol 267:55-68.

Sur M, Garraghty PE, Roe AW (1988) Experimentally induced visual projections into auditory thalamus and cortex. Science 242:14371441.

Tessier-Lavigne M, Placzek M, Lumsden AGS, Dodd J, Jessell TM (1988) Chemotropic guidance of developing axons in the mammalian central nervous system. Nature 326:775-778.

Thanos S, Bahr M, Barde Y-A, Vanselow J (1989) Survival and axonal elongation of adult rat retinal ganglion cells. In vitro effects of lesioned sciatic nerve and brain derived neurotrophic factor. Eur $\mathbf{J}$ Neurosci 1:19-26.

Thompson I, Holt C (1989) Effects of intraocular tetrodotoxin on the development of the retinocollicular pathway in the Syrian hamster. J Comp Neurol 282:371-388.

Tsai G, Stauch BL, Vornov JJ, Deshpande JK, Coyle JT (1990) Se- lective release of $N$-acetylaspartylglutamate from rat optic nerve terminals in vivo. Brain Res 518:313-316.

Vidal-Sanz M, Bray GM, Villegas-Perez MP, Thanos S, Aguayo AJ (1987) Axonal regeneration and synapse formation in the superior colliculus by retinal ganglion cells in the adult rat. J Neurosci 7:28942909.

Vidal-Sanz M, Bray GM, Aguayo AJ (1991) Regenerated synapses persist in the superior colliculus after the regrowth of retinal ganglion cell axons. J Neurocytol 20:940-952.

Vielmetter J, Stuermer CAO (1989) Goldfish retinal axons respond to position-specific properties of tectal cell membranes in vitro. Neuron 2:1331-1339.

Walter J, Kern-Veits B, Huf J, Stolze B, Bonhoeffer F (1987a) Recognition of position-specific properties of tectal cell membranes by retinal axons in vitro. Development 101:685-696.

Walter J, Henke-Fahle S, Bonhoeffer F (1987b) Avoidance of posterior tectal membranes by temporal retinal axons. Development 101:909913.

Walter J, Muller B, Bonhoeffer F (1990) Axonal guidance by an avoidance mechanism. J Physiol (Paris) 84:104-110.

Westerbrook GL, Mayer ML, Namboordi MAA, Neale JH (1986) High concentrations of $N$-acetylaspartylglutamate (NAAG) selectively activate NMDA receptors in mouse spinal cord neurons in cell culture. J Neurosci 6:3385-3392.

Yoon MG (1971) Reorganization of retinotectal projection following surgical operations on the optic tectum in the goldfish. Exp Neurol 33:395-411.

Zwimpfer TJ, Aguayo AJ, Bray GM (1989) Synapse formation by regenerating retinal ganglion cell axons directed into an inappropriate target (the cerebellar cortex) in adult hamsters. Soc Neurosci Abstr $15: 458$.

Zwimpfer TJ, Inoue HI, Aguayo AJ, Bray GM (1990) Regenerating retinal ganglion cell axons can form synapses with neurons in four different non-retinal targets in the adult hamster. Soc Neurosci Abstr $16: 41$. 